
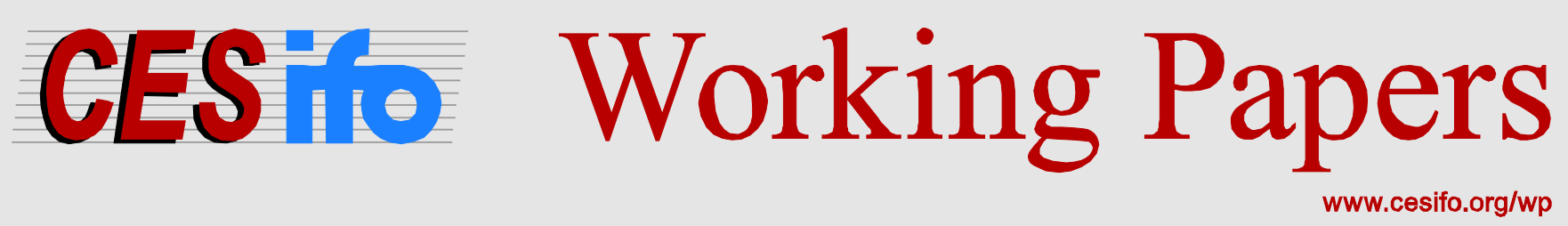

\title{
The Geography of Natural Resources, Ethnic Inequality and Development
}

\author{
Christian Lessmann \\ Arne Steinkraus
}

\author{
CESIFO WORKING PAPER NO. 6299 \\ CATEgory 6: Fiscal POLICY, MACROECONOMICS AND GROWTH \\ JANUARY 2017
}

An electronic version of the paper may be downloaded

- from the SSRN website:

- from the RePEc website:

- from the CESifo website:

www.SSRN.com

www.RePEc.org

www.CESifo-group.org/wp 


\title{
The Geography of Natural Resources, Ethnic Inequality and Development
}

\begin{abstract}
We study whether the spatial distribution of natural resources across different ethnic groups within countries impede spatial inequality, national economic performance, and the incidence of armed conflict. By providing a theoretical rent-seeking model and analysing a set of geocoded data for mines, night-time light emissions, local populations and ethnic homelands, we show that the distribution of resources is a major driving factor of ethnic income inequality and, thus, induces rent-seeking behaviour. Consequently, we extend the perspective of the resource curse to explain cross-country differences in economic performance and the onset of civil conflicts. We show that the inequality in the spatial distribution of resource endowments within countries drives the curse of natural resources, not the resources per se.
\end{abstract}

JEL-Codes: D720, D740, Q320, Q340.

Keywords: natural resources, minerals, mines, night lights, luminosity, ethnic income inequality, spatial inequality, development, civil war, conflict.

\author{
Christian Lessmann* \\ TU Braunschweig \\ Institute of Economics \\ Spielmannstr. 9 \\ Germany - 38106 Braunschweig \\ c.lessmann@tu-braunschweig.de
}

\author{
Arne Steinkraus \\ TU Braunschweig \\ Institute of Economics \\ Spielmannstr. 9 \\ Germany-38106 Braunschweig \\ a.steinkraus@tu-braunschweig.de
}

*corresponding author

We are grateful to the seminar participants of the 5th Workshop on Regional Economics and the 10th CESifo Workshop on Political Economy for their helpful comments. An earlier version of this paper was circulated under the title "Natural Resources in Ethnically Divided Countries: A Blessing for Regions but a Curse for Nations". 


\section{Introduction}

This paper investigates whether the spatial distributions of natural resources across different ethnic groups within countries impede spatial income inequality, the incidence of armed conflict, and national economic performance.

Many existing studies analyse the so-called "natural resource curse" in which the economies of states that are resource rich tend to growth slower than those of countries that are resources scarce (see, e.g., Sachs and Warner 1995, 2001). The theoretical transmission channels are numerous, including rent-seeking, Dutch disease, and corruption (see section 2 for a detailed review of the literature). A clear majority of empirical studies concentrates on country-level data that are widely available for countries at different levels of economic development. However, country-level averages ignore the spatial distributions of resources within countries, which may be very important for several transmission channels.

We study the effects of spatially unequal resource distribution on ethnic income inequality, civil war and economic performance. Consequently, our paper relates to three broad strands of the literature. First, this paper enlarges the perspective of the resource curse on spatial fractionalisation and geography-driven causes of underdevelopment. We argue that inequality in resource endowments is the driving force in this context, not a country's resources endowment per se. Second, it is still unknown to what extent heterogeneous resource distribution drives income inequality within countries. The recent literature only states that resources raise personal income inequality in ethnically divided countries but reduces inequality in homogenous societies (Fum and Hodler 2010). We therefore provide new insights into exogenous roots of horizontal inequalities within countries. Third, this paper contributes to the existing literature on the causes of civil war. Most studies focus on the economic and institutional roots of civil war. Few of them include exogenous geographical data, which is said to favour insurgency (see Fearon and Latin 2003, Morelli and Rohner 2015).

Our study is motivated by a theoretical model that extends Hodler (2006) to the case of unequal resource distribution across groups. We hypothesise that (1) a group, endowed with a certain resource, participates in growing rents more than other groups and that (2) intergroup income inequality grows as resource inequality rises. Additionally, we argue that, on average, (3) an unequal distribution of resources is associated with low productivity. Therefore, the distribution of resources across different groups is a driving factor of a society's economic performance. 
Considering conflicts as a transmission channel, we claim that (4) a heterogeneous resource distribution increases the probability of the onset of civil war.

We exploit night-time light data for mining areas and ethnic homelands to test our main hypotheses. Ethnic homelands are defined as in the Geo-Referencing of Ethnic Groups (GREG) data set, which is derived from the Soviet Atlas Narodov Mira (Weidmann et al. 2010). Following Alesina et al. (2016), we use the light intensity within ethnic homelands to proxy for ethnic income and inequality. Concerning resource rents, we concentrate on the geo-locations of active mines, which are reported by the National Minerals Information Center of the U.S. Geological Survey. We draw circles with a $10-\mathrm{km}$ radius around the exact locations of more than 6,000 mines and mining facilities all over the world, ${ }^{3}$ and we calculate the levels and changes of night-time light in these areas. Our approach is based on the assumption that an increase in mining intensity causes an increase in light emissions on the earth's surface due to local lighting and transport systems, industrial facilities and agglomerations of miners. In order to test our approach, we consider two cases in detail: Mt. Whaleback, an iron ore mine in Western Australia, and El Teniente, a copper mine in Chile. Both examples show that mine lights are closely related to both input and output measures of resource extraction, regardless of whether the mine has an open pit or an underground pit. Moreover, we show that changes in mine-lights calculated at the country level are highly correlated with reported information on mineral resource rents drawn from the World Development Indicators. Therefore, our approach seems suitable for measuring the intensity of resource extraction at the local level.

Our panel regressions, which use country- and ethnicity-level data, suggest that rent-seeking activities are low in countries that are ethnically homogeneous or have resources that are homogeneously distributed across ethnicities, while rent seeking increases as heterogeneity rises. In line with our theory, resource inequality is a crucial determinant of ethnic income inequality, conflicts and economic performance. In particular, we show that increased mine-lights are associated with rising income for the specific ethnic group surrounding the mining area. Neighbouring ethnicities do not gain from resource exploitation behind ethnic borders. Moreover, we calculate an inequality index at the country level (MineralGINI), which measures the concentration of mine light across ethnicities. Panel fixed effects regressions show that an unequal resource distribution increases ethnic income inequality, decreases productivity and increases the risk of internal conflicts. Importantly, we find that an increase in the intensity of resource

\footnotetext{
${ }^{3}$ At this, we exclude the U.S. because the data report a much higher density of mines here, which suggests a bias in the reporting system.
} 
extraction unambiguously increases regional and national income when the resource distribution is homogeneous, while national income is negatively affected by an unequal distribution of the resource endowment. Therefore, natural resources are a blessing for regions, but they may be a curse for nations.

Let us briefly illustrate our findings in the cases of Nigeria and Gabon. These countries have almost the same degree of ethnic fractionalisation. However, according to our Gini index of resource inequality, Nigeria has very high resource concentration across ethnicities of approximately 0.88 , whereas Gabon's mine-light inequality is significantly lower, with an index of 0.62. Inequality in resource distribution causes comparatively high ethnic income inequality in Nigeria whose Gini index is 0.71 compared to 0.41 in Gabon. In addition, Nigeria has a low average Gross Domestic Product (GDP) of \$ 4,404 per capita (measured in 2011 international Purchasing Power Parity (PPP) \$) and suffered from at least three armed conflicts during our 2000-2012 observation period. On the contrary, Gabon's GDP is $\$ 16,937$, and there has not been a single conflict over the entire period. Considering the full sample, we find that a 0.1 increase in the resource inequality Gini is associated with a 0.035 higher income Gini, which increases the probability of the onset of civil war by approximately $0.7 \%$ and decreases the national level of real GDP by $1 \%$, on average. Therefore, by taking into account the intra-national spatial distribution of natural resources, we are confident that our study provides new insights into the economics of the resource curse.

The remainder of this paper is structured as follows. Section 2 discusses the related literature. Section 3 provides a theoretical model based on Hodler (2006), which we extend to the case of unequal resource distribution. Section 4 introduces the data, which are used to test our main hypotheses. Section 5 concludes.

\section{Related literature and research question}

The natural resource curse was first mentioned by Wheeler (1984), who found that growth rates of mineral-poor countries in Sub-Saharan Africa (SSA) exceeded the growth rates of mineralabundant countries. However, the hypothesis that resource-abundant countries may suffer from low growth rates did not attract much attention until Sachs and Warner $(1995,1997)$ found a negative correlation between economic performance and resource exports as a share of the GDP. Subsequently, many case studies of resource-abundant countries have supported the cross-country results (see, e.g., Lane and Tornell 1996, 1999, Ross 2001, Han et al. 2007, Salai-Martin and Subramanian 2013). 
The transmission channels between resource abundance and economic performance are numerous, including the Dutch disease (Cordon and Neary 1982, Bruno and Sachs 1982, Usui 1997), poor institutional quality (Mehlum et al. 2006, Robinson et al. 2006), and corruption (Gerlagh and Papyrakis 2004). ${ }^{4}$ Our study is also closely related to two more recent strands of the literature: the link between natural resources and civil conflict and role of ethnic fractionalisation or polarisation.

The link between natural resources and civil conflicts has been extensively studied by Collier and Hoeffler $(1998,2004,2005)$. They show that natural resource abundance determines the duration of civil wars, as well as the probability of onset. On the contrary, Brunnschweiler and Bulte (2009) argue that the particular measure of resource abundance matters. If deposits rather than export ratios are taken into account, the negative relationship between natural resources and civil wars vanishes. However, these studies focus on aggregate, country-level data and do not explain interregional or cross-country differences in the occurrence of the curse. More recent approaches provide better insights by extending this perspective using high-resolution geocoded data. These data allow the analysis of small administrative regions, ethnic homelands or even grids, which are independent of political or social borders. Arezki et al. (2015) use geocoded data on resources, conflicts and night-time light emissions to construct a quasi-natural experiment to study the causal link between resource discoveries and the onset of intrastate civil war. They find that such windfalls increase the probability of the onset of war after at least four years because of the lag between discovery and the start of production. Berman et al. (2015) perform a similar analysis but focus on the effects of exogenous variation in world prices. According to their empirical strategy, historical increases in prices explain approximately 20 per cent of average country-level conflicts in Africa.

Ethnicity matters, too. Ethnic fractionalisation and polarisation negatively impact long-term economic performance (Easterly and Levine 1997, Alesina et al. 2003) and are influential determinants of civil conflict (Esteban and Ray 1994, Esteban et al. 2012). Importantly, ethnicity also plays a moderating role in the resource-conflict nexus, as well as in the resource-underdevelopment nexus. Morelli and Rohner (2015) investigate the effects of resources, especially oil and ethnic group regional concentration, on ethnic conflicts, such as secessionist wars. They find that civil wars are more likely to occur if small ethnic groups are particularly rich in natural resources. Hodler (2006) analyses the impact of ethnic fractionalisation on the emergence of the resource curse using a rent-seeking model. He assumes that there is a common resource

\footnotetext{
${ }^{4}$ For a detailed review of the literature, see Rossner (2006).
} 
stock that is distributed across ethnicities according to their fighting input. He finds that rentseeking behaviour, which is driven by ethnic fractionalisation, contributes substantially to cross-country differences in economic performance and institutional quality. In addition, he provides empirical evidence for his theoretical model using aggregate, country-level data.

Existing empirical studies on the natural resource curse suffer from at least two problems. First, they investigate the resource curse using different figures, such as export ratios, resource rents or wealth in deposits. Although all these figures seem to be appropriate at first glance, they are highly endogenous when it comes to analysing the effect of resources on economic performance. For example, high shares of mineral rents in GDP reveal the lack of other productive activities whereas huge reserves outline the economy's advanced technology to detect those deposits (van der Ploeg \& Poelhekke 2016). To gain some exogenous variation in the resource data and to account for increasing fighting activities, studies that analyse the effect of resources on conflicts often include the world price of the resource. However, this procedure is problematic. Dube and Vargas (2013) note that increasing commodity prices come with an opportunity cost as well as with a rapacity effect. Depending on which effect dominates, increasing resource prices either mitigate or fuel conflicts. Therefore, the effect of price on the onset of intrastate conflict is ambiguous. Furthermore, people in poor and less-developed countries, which are said to suffer heavily from the resource curse, do not gain from price increases or other windfalls. Foreign companies or corrupt politicians often benefit instead. This problem may be why studies using different resource figures sometimes find ambiguous effects. Hence, it is important to eliminate price-induced effects. By focusing on mine-light emissions as a proxy for local exploitation rates, we can reduce this potential source of bias.

Second, due to a lack of useful data, especially for African countries, usually the effects of resources and income are studied at the country level. Thus, these studies neglect the consequences of a spatially heterogeneous resource distribution, especially across ethnicities. Since recent studies by Aragón and Rud (2013) and Munasib and Rickman (2015) outline the positive local effect of resources, this issue may be one of the main drivers of rent-seeking activities. It may in turn lead to the emergence of an economic resource curse or even to intrastate civil war.

Our main research questions are the following: Do differences in initial resource endowments across ethnicities contribute to rent-seeking behaviour? How does resource inequality affect ethnic income inequality? How do these inequalities feed back into the risk of conflict and national development? 
To answer these questions, we adapt Hodler's (2006) approach and provide a theoretical framework for (local) rent seeking that allows us to analyse potential outcomes conditional on different initial resource distributions across ethnicities. This framework serves as the foundation for the subsequent empirical analysis in which we aim to unify the different approaches by exploiting geo-coded data, which allow us to prescind from resource prices and investigate local incomes from resource revenue and income distributions across ethnic homelands.

\section{Model}

In ethnically fractionalised societies that possess natural resources, groups may put effort into rent-seeking, fighting or defence activities. This effort cannot be used for other productive activities, such as labour, and therefore impose opportunity costs on the society. Hodler (2006) analyses this rent-seeking effect on income, assuming that resources are a common pool. Providing theoretical and empirical evidence, he shows that rent-seeking activity is high in ethnically fractionalised countries. However, in many cases, natural resources are not equally distributed across ethnic groups; therefore, it is inappropriate to assume that these are "standard" common pool resources. Consequently, the question arises of whether an initially unequal resource distribution within countries affects rent-seeking activities giving rise to a resource curse phenomenon. In order to answer this research question, we extent Hodler (2006) by permitting individual initial resource stocks across groups. Thanks to detailed geo-coded data on the exact locations of natural resources and ethnic incomes, we are able to test our main hypothesis empirically (section 3).

In the next subsection, we present a one-shot Cournot game that allows us to analyse the effects of different resource distributions across ethnicities on income, income inequality and the probability of the onset of civil war. We first explain the general setup of the model and derive the reaction functions. Second, we perform a case-by-case analysis to determine the equilibria of different resource distribution settings. Third, we derive the main hypothesis for the empirical analysis presented in section 3.

\subsection{General setup}

We study a country whose total workforce $X$ is divided into $N \geq 1$ different groups. The number of groups is taken as exogenous. Each rival group is assumed to be equally sized such that they are endowed with the same workforce $x_{i}=\frac{X}{N} \forall i=1, \ldots, N$. This assumption is necessary since we want to focus our analysis on differences in resource endowments across groups 
rather than on fractionalisation or polarisation issues. Importantly, we assume that the group's resource endowment is determined by the place of residence, which is independent from the resource itself. Thus, each group owns a certain quantity $\omega_{i}$ of the total amount of resources $\Omega$, where the following constraints must hold:

$$
\begin{gathered}
\omega_{i} \in[0, \ldots, \Omega] \forall i=1, \ldots, N \\
\sum_{i=1}^{N} \omega_{i}=\Omega
\end{gathered}
$$

As a result of imperfect property rights over natural resources, the groups have to decide whether to allocate their workforce to productive activities $l_{i}$ or to rent-seeking activities, such as fighting and defence $f_{i}$ :

$$
x_{i}=l_{i}+f_{i}
$$

This allocation problem is driven by a rational income maximisation decision. In particular, each group tries to maximise its income

$$
\max y_{i}=A \cdot l_{i}^{\alpha} \cdot r_{i}^{1-\alpha}
$$

where $y_{i}$ denotes the total income, $A$ the technological progress factor, $\alpha$ the standardised income elasticity with respect to productive activities, such as labour, and $r_{i}$ the resource group $i$ appropriates. Each group's share of the resource is the result of insecure property rights, fighting activities and, thus, rent-seeking behaviour. We model resource rents as a linear combination of local resources that are protected by property rights and the sum of non-protected national resources that are divided across groups according to their share of total fighting activity

$$
r_{i}=p \cdot \omega_{i}+\frac{f_{i}}{F} \cdot(1-p) \cdot \Omega
$$

where $F$ is the sum of all $f_{i}$, and $p$ denotes the level of property rights, which is bounded between 0 and 1. We follow Hodler (2006) in assuming that property rights are an endogenous result of the input share that is allocated to fighting activities: 


$$
p=1-\frac{F}{X}
$$

This approach is quite intuitive because increasing fighting activity makes it difficult for a group to keep control of its own resources. As a consequence, we can rewrite the rent equation in the following way:

$$
r_{i}=\left(1-\frac{F}{X}\right) \cdot \omega_{i}+\frac{f_{i}}{F}\left(1-\left(1-\frac{F}{X}\right)\right) \cdot \Omega=\left(1-\frac{F}{X}\right) \cdot \omega_{i}+\frac{f_{i}}{X} \cdot \Omega
$$

Given this information, we can solve the Cournot game. We receive reaction functions, since all groups maximise their income by choosing their workforce allocations simultaneously. Specifically, the functions we are looking for are the fighting activities $f_{i}$ that maximise each group's income given the other groups' fighting activities $f_{-i}$. We derive the reaction function using Lagrange formalism. Maximising income (4) conditional on the workforce allocation (3) as well as the available resources (7) yields:

$$
\mathcal{L}=A \cdot l_{i}^{\alpha} \cdot r_{i}^{1-\alpha}+\mu \cdot\left(x_{i}-l_{i}-f_{i}\right)+\lambda \cdot\left(\left(1-\frac{F}{X}\right) \cdot \omega_{i}+\frac{f_{i}}{X} \cdot \Omega-r_{i}\right)
$$

leading to the following first-order conditions

$$
\begin{gathered}
\frac{\partial \mathcal{L}}{\partial l_{i}}=A \cdot \alpha \cdot\left(\frac{r_{i}}{l_{i}}\right)^{1-\alpha}-\mu=0 \\
\frac{\partial \mathcal{L}}{\partial f_{i}}=-\mu+\lambda \cdot\left(-\frac{\omega_{i}}{X}+\frac{\Omega}{X}\right)=-\mu+\lambda \cdot \frac{\omega_{-i}}{X}=0 \\
\frac{\partial \mathcal{L}}{\partial r_{i}}=A \cdot(1-\alpha) \cdot\left(\frac{r_{i}}{l_{i}}\right)^{\alpha}-\lambda=0
\end{gathered}
$$

where $\mu$ denotes the shadow price of one additional unit of the workforce share, $\lambda$ is the shadow price of one additional unit of resource rents, and $\omega_{-i}$ is the resource rents of all other groups. Dividing (11) by (9) and substituting into (10) yields:

$$
\frac{\alpha}{1-\alpha} \cdot \frac{r_{i}}{l_{i}}=\frac{\omega_{-i}}{X}
$$


Using the labour allocation constraint (3) and equation (12), we can derive the reaction function:

$$
f_{i}^{R}\left(f_{-i}\right)=(1-\alpha) \cdot \frac{X}{N}+\alpha \cdot\left(f_{-i}-X\right) \cdot \frac{\omega_{i}}{\omega_{-i}}
$$

\subsection{Case-by-case analysis}

The $\frac{\omega_{i}}{\omega_{-i}}$ ratio in the reaction function shows that the resource distribution across different rival groups is a major driving factor in determining the Nash equilibria. Thus, we compare the potential outcomes of our model considering two extreme initial conditions. First, we determine the Nash equilibrium for the case of absolutely homogeneous resource distribution, which is the reference case discussed by Hodler (2006). Second, we analyse the interactions of all groups' reaction functions when one group possesses (almost) all the initial resources.

\section{Homogeneous distribution}

If we assume a homogeneous resource distribution, each group is endowed with the same initial amount of resources $\omega_{i}=\frac{\Omega}{N}$. The factor $\frac{\omega_{i}}{\omega_{-i}}$ in equation (13) becomes $\frac{1}{N-1}$, and the same reaction function holds for all groups. Since all groups behave in the same way and choose the same fighting activity, we use $f_{-i}=(N-1) \cdot f_{i}$ to simplify equation (13), which yields the following equilibrium fighting activity

$$
f^{E}=\left(1-\frac{\alpha}{1-\alpha} \cdot \frac{N}{N-1}\right) \cdot x_{i}
$$

if $\frac{\alpha}{1-\alpha} \cdot \frac{N}{N-1}<1$ and $f^{E}=0$ otherwise. This result is in line with Dube and Vargas (2013), who find that the high opportunity costs of reducing labour, which are reflected in a high $\alpha$ in our model, tend to decrease the incentive to fight for resources.

Using (14) to determine the equilibrium income, it follows that:

$$
y_{i}=A \cdot\left(x_{i} \cdot \frac{\alpha}{1-\alpha} \cdot \frac{N}{N-1}\right)^{\alpha} \cdot\left(\frac{\Omega}{N}\right)^{1-\alpha}
$$

Consequently, the country-level total income is: 


$$
Y=N \cdot y_{i}=A \cdot\left(X \cdot \frac{\alpha}{1-\alpha} \cdot \frac{N}{N-1}\right)^{\alpha} \Omega^{1-\alpha}
$$

The factor $\left(\frac{\alpha}{1-\alpha} \cdot \frac{N}{N-1}\right)^{\alpha}$ (given that $\frac{\alpha}{1-\alpha} \cdot \frac{N}{N-1}<1$ ) describes rent-seeking losses due to fractionalisation, where the larger the number of groups $N$ that compete over resources, the lower the country-level income. This result confirms prior studies (see, e.g., Easterly and Levine 1997, Hodler 2006).

\section{Heterogeneous Distribution}

Next, we describe the other extreme, assuming an (almost) perfectly unequal distribution of resources. Because of the analytical constraints of the model, we assume that the total amount of resources $\Omega$ is much larger than the number of groups $\mathrm{N}(\Omega \gg N ; \Omega-N \approx \Omega)$. If one thinks of a resource, e.g., as the rents from minerals, in terms of \$US and takes into account that the number of rival groups is rarely above 20 , this assumption is not problematic. Hence, we analyse the equilibrium for the case in which one group is endowed with almost all resources $\omega_{i} \approx$ $\Omega$ and all other groups possess a very small amount $\omega_{j}=1 \forall j \neq i$. The resulting reaction function of group $i$ can be written as:

$$
f_{i}\left(f_{-i}\right)=(1-\alpha) \cdot x_{i}+\alpha \cdot \frac{\Omega}{N-1} \cdot f_{-i}-\alpha \cdot \frac{\Omega}{N-1} \cdot X
$$

From group $i$ 's point of view, the other groups' fighting activity can be written as $f_{-i}=(N-1) \cdot f_{j}$ because the other groups act all the same way. Using the simplifications mentioned above and the condition that $f_{-j}=f_{i}+(N-2) \cdot f_{j}$, each group's fighting activity results in:

$$
f_{j}\left(f_{i}\right)=(1-\alpha) \cdot x_{j}+\frac{\alpha}{\Omega} \cdot\left(f_{i}-X\right)
$$

Taking equations (17) and (18) into account, the equilibrium fighting activities can be approximated by:

$$
\begin{gathered}
f_{i} \approx 0 \\
f_{j} \approx x_{j} \cdot(1-\alpha) \forall j \neq i
\end{gathered}
$$


Since group $i$ initially owns all the resources, their returns to allocating the workforce towards fighting activities are very small. They can only protect their resources; they have no chance to benefit from other groups' resources. Additionally, the costs of reallocating the workforce are comparatively high. The net return of reallocation is negative. Therefore, group $i$ refuses to perform any fighting activities. Using equations (19) and (20), the groups' income can be calculated:

$$
\begin{gathered}
y_{i} \approx A \cdot x_{i}^{\alpha} \cdot\left[\left(1-\frac{(N-1) \cdot(1-\alpha)}{N}\right) \cdot \Omega\right]^{1-\alpha} \\
y_{j} \approx A \cdot\left(\alpha \cdot x_{i}\right)^{\alpha} \cdot\left[\frac{(1-\alpha)}{N} \cdot \Omega\right]^{1-\alpha} \forall j \neq i
\end{gathered}
$$

\subsection{Hypotheses}

To determine the effects of unequal resource distribution on economic performance, inequality and the probability of civil war, ${ }^{5}$ we compare the first derivatives of $y_{i}$ and $y_{j}$ in the heterogeneous case with respect to the total amount resources $\Omega$. We find that $\frac{\partial y_{i}}{\partial \Omega}>\frac{\partial y_{j}}{\partial \Omega}$. Taking this result into account and considering the income distribution in the homogeneous case, the following two hypotheses become obvious:

H1: A group, endowed with a certain resource, participates in growing rents more than other groups.

\section{H2: Income inequality grows as resource inequality rises.}

Comparing the total fighting effort spent in the homogeneous and heterogeneous cases is not as easy as calculating derivatives because these amounts depend on the number of groups $N$ as well as on the labour elasticity $\alpha$. Thus, we compute total effort as a function of $\alpha$ and $N$ and plot the result (Figure D 1 in Appendix D).

Considering the constant returns to scale and positive but decreasing marginal productivity of each input variable, high total fighting activity is associated with low incomes, on average. Therefore, we hypothesise the following:

\footnotetext{
${ }^{5} \mathrm{We}$ are not interested in the effects of $\alpha$ and $N$ because their impacts are extensively studied in Hodler (2006), and we do not find diverging results.
} 
H3: An unequal distribution of resources is associated with low productivity, on average, for a broad range of $\alpha$. Therefore, the distribution of resources across different groups has a major impact on a society's economic performance.

H4: A heterogeneous resource distribution increases the probability of the onset of civil war for a broad range of elasticities $\alpha$.

The data that are used to test the hypotheses in the empirical part of this paper are outlined in the following section.

\section{Empirical analysis}

In this section, we test our main hypothesis using geo-coded regional- and country-level data. The subsequent section 4.1 provides the details on the data and our measurement concepts for the intensity of local resource extraction and the inequality of resource endowments. Section 4.2 provides the estimation results.

\subsection{Data}

We concentrate on three different types of data: i) satellite night light, ii) mine locations, and iii) boundaries of ethnic homelands. i) Satellite night light data are provided by the National Oceanic and Atmospheric Administration (NOAA) and the National Geophysical Data Center (NGDC). We refer to the stable lights product to which several corrections have been made to the raw data to isolate man-made light emissions from other sources. These data have frequently been used to proxy for income at the national or sub-national level (e.g., Elvidge et al. 1997, Chen and Nordhaus 2011, Henderson et al. 2012, Wu et al. 2013, Lessmann and Seidel 2017, and Alesina et al. 2016). The main advantage of these data is that they are available at a high resolution of approximately $1 \mathrm{~km}^{2}$, which allows for the analysis of different levels of aggregation, such as administrative regions, ethnic homelands, grids or mining areas. In our study, the light data have two different but related functions. As in the existing literature, we use luminosity to proxy for consumption and production across (ethnic) regions and countries. We assume that an increase in light intensity is associated with an increase in the income of the observed unit. In addition, we use night light to measure the intensity of resource extraction of mines at the local level. The original data reports a digital number (DN) between 0 and 63 , where 0 reflects dark pixels and 63 the highest detected luminosity.

ii) A geo-coded data set on mineral operations is provided by the National Minerals Information Center of the U.S. Geological Survey. It contains information on the locations of facilities that 
were active at least one year between 2003 and 2007. Facilities not only include mines but also related industry facilities, such as those for ore refining. Since the data set is more comprehensive inside the U.S., we exclude the U.S. from our analysis to avoid sample selection bias. The data set contains information on more than 12,000 mines around the world, of which 6,478 are outside the U.S. To measure the intensity of local resource extraction, we draw circles with a radius of $10 \mathrm{~km}$ (approximately six miles) around the geo-locations of mines and measure luminosity by summing up the DN values of all pixels within that area. Let us consider an example to understand these dimensions. The largest mine in the world, the Bingham Canyon Mine southwest of Salt Lake City, is approximately $4.0 \mathrm{~km}$ wide and covers approximately $8 \mathrm{~km}^{2}$. The area that we observe by drawing circles is $314 \mathrm{~km}^{2}$, which is approximately the landmass of the city of Pittsburgh. We therefore do not focus only on the mine itself, which is important for two reasons. First, by drawing larger circles, we measure the light intensity of a wider area, which hosts, for example, related industry facilities, transport infrastructure, and storage facilities. Second, the data set does not include small-scale or illegal mines. However, minerals are very often spatially clustered. Hence, our approach of drawing larger circles around the geolocations of mines also captures these small mines and their economic activity. Finally, our approach has the advantage of allowing us to observe the production of mines at the local level in a time-varying manner.

Figure 1 illustrates the relationships among mine size, production intensity and luminosity using two examples: the Mount Whaleback Iron Ore Mine, which is in Western Australia, and El Teniente, a copper mine in Chile. The left panels show figures for 2005 (resp. 2007), the right panel for 2013. We compare satellite daytime images from Google Earth in the upper rows with the night-time light emissions below. An important difference is that Mount Whaleback is an opencast pit, while El Teniente is underground. The daytime images of Mount Whaleback show a significant increase in the area covered by the mine as well as in the number of buildings. During the observation period, the number of employed persons increased from 1,719 to 2,814. The satellite night light images below also show a significant increase in luminosity emitted by the mine. Both the intensity and the range of lights increased over time. If we calculate the sum of lights (DN values from the original data) in the circle with $10-\mathrm{km}^{2}$ radius, we find that light emissions increased from 2,432 to 5,111 DN. This dimension fits the employment statistics. The growth of employment was approximately $38 \%$, and the growth of night light was $110 \%$. Turning our attention to the daytime images of El Teniente, we observe the beginning of an additional sedimentation basin in the southwest and new construction of logistic buildings west 
of the mineshaft. Emissions of night-time light increased from 2,491 to 3,485 DN (40\%) between 2007 and 2013. By comparison, we find that the output of the mine increased from $405 \mathrm{kT}$ copper to $450 \mathrm{kT}(11 \%)$. Both examples suggest that light emissions from mines are a suitable indicator of resource extraction at the local level. However, the type of the mine and the particular mineral that is exploited affects the output-light relationship. Therefore, it is not possible to compare light levels across mines. Consequently, our forthcoming empirical investigation focuses on fixed effects regressions, which take differences in light levels into account. 


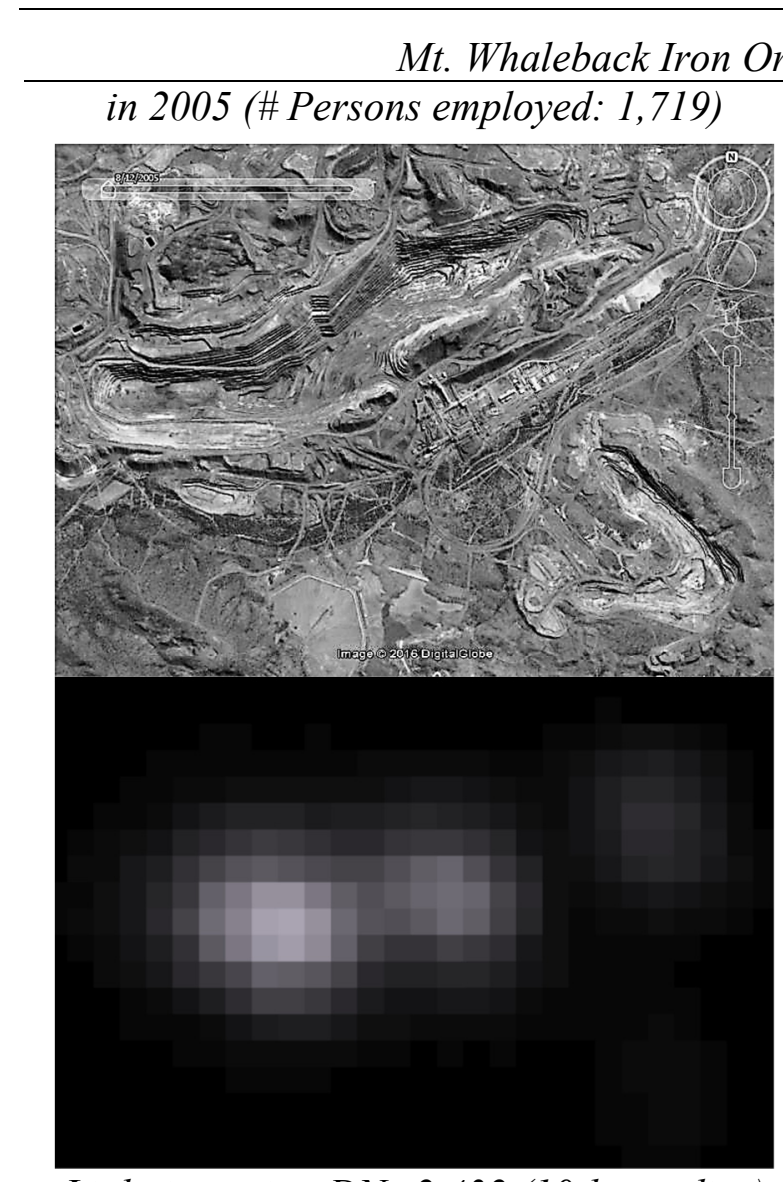

Light intensity: $D N=2,432$ (10- $\mathrm{km}$ radius)

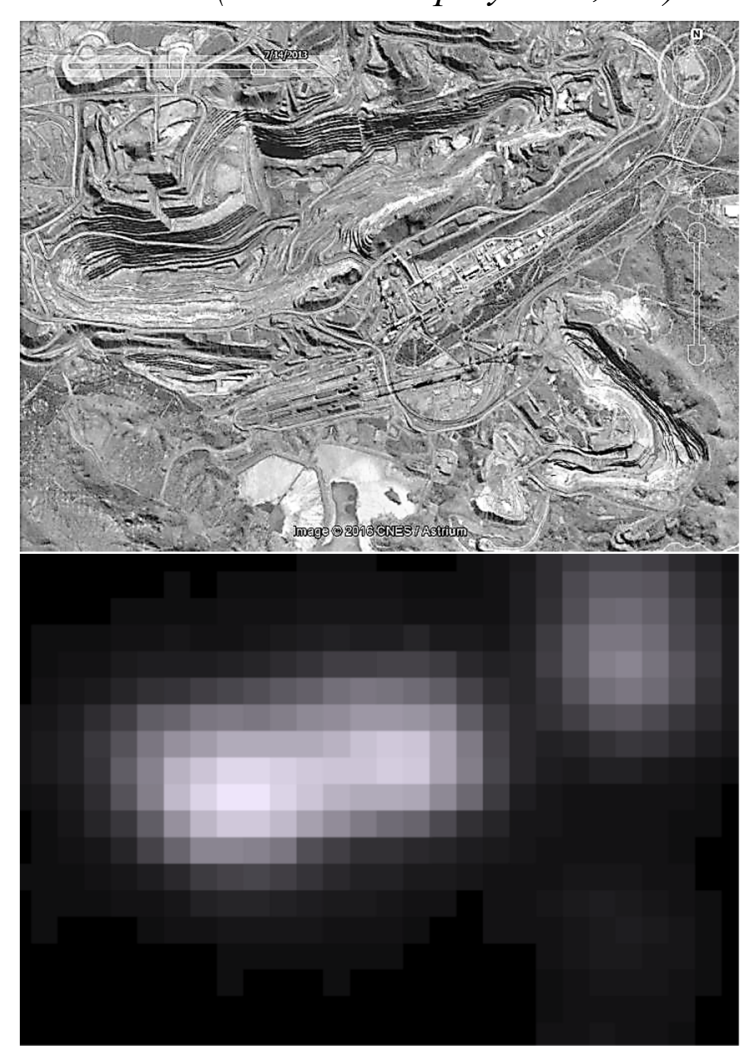

Light intensity: $D N=5,111$ (10-km radius)

\section{El Teniente Underground Copper Mine, Chile}

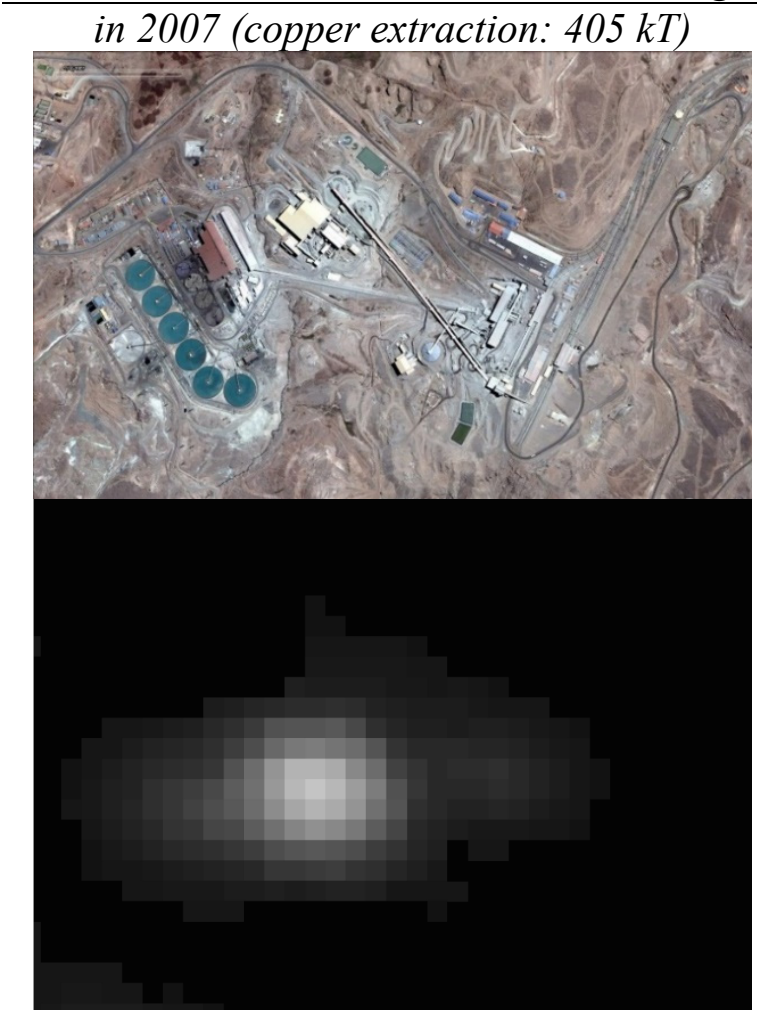

Light intensity: $D N=2,491$ (10-km radius) in 2013 (copper extraction: $450 \mathrm{kT}$ )

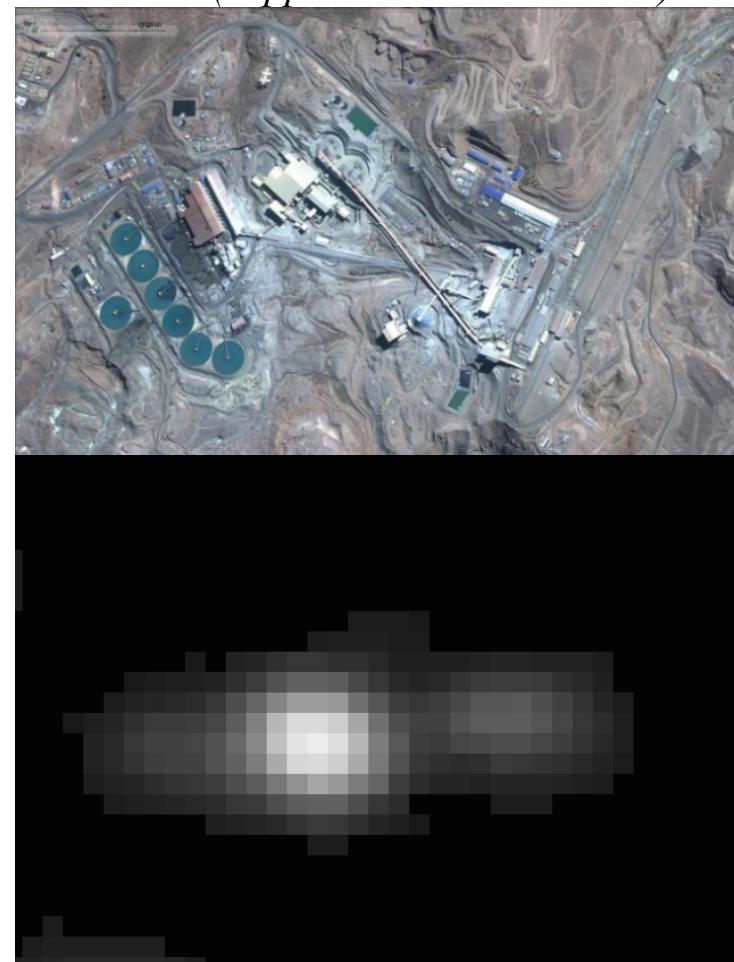

Light intensity: $D N=3,485$ (10-km radius)

Figure 1:Daytime and night-time satellite images of mines. 
The major advantage of our approach is that we can construct a time-varying proxy for resource extraction at the local level, which is important to study the effects of an unequal resource distribution on economic and social outcomes. The examples show that mine light correlates with both input and output measures of mining intensity. However, this does not necessarily imply that mineral resource rents increase, too. Of course, more miners earn higher incomes, which we expect to remain local and increase the incomes of nearby regions. However, the net revenues of resource extraction may also fall, if for example, more miners are needed to extract a decreasing resource stock. Mines become deeper over time, and the mineral content of the rocks decreases as the mine approaches the threshold at which further extraction becomes cost inefficient. Another issue concerns resource prices, which directly affect resource rents; therefore, mine lights must not necessarily proxy for resource rents. This is difficult to test at the mine level, particularly because we do not know the exact composition of the extracted minerals. What we can show is a correlation between mineral resource rents, as reported by the World Development Indicators, and the sum of lights emitted by all mines within a country. The results are reported in Table 1 for all countries for which data on resource rents are available. The correlation between mine lights and resource rents is usually positive and significantly different from zero. Only in three cases, Denmark, Jamaica (both resource poor) and Montenegro (resource rich), is the correlation coefficient negative and significantly different from zero. Nevertheless, we are confident that our mine light indicator can also be interpreted as a proxy for resource rents at the local level.

iii) The Geo-Referencing of Ethnic Groups (GREG) data set provided by Weidmann et al. (2010) is derived from the Soviet Atlas Narodov Mira from 1964 that contains the geo-referenced coordinates of the boundaries of most ethnic groups. In total, it contains data from 1,120 ethnic groups, which are divided into more than 8,000 regions. Most of the earth is covered. Since ethnic group membership is exogenous, it applies very well to our theoretical model. As noted by Morelli and Rohner (2015), the use of these comparatively old geographical boundaries has advantages as well as disadvantages. On the one hand, the fact that these ethnic boundaries pre-date our active mines data set and other data helps mitigate concerns that these boundaries are endogenous either to the existence of point resources or to wars. On the other hand, these boundaries may now be inaccurate. This fact adds some extra noise to our estimations that reduces both the significance and the magnitude of the coefficients. Fortunately, ethnic boundaries shift very slowly. 
Table 1: Correlation between light emissions and resource rents by country

\begin{tabular}{|c|c|c|c|c|c|c|c|}
\hline Country & Coeff. & Country & Coeff. & Country & Coeff. & Country & Coeff. \\
\hline ALB & 0.121 & ECU & $0.777 * *$ & KAZ & $0.651 \%$ & POL & 0.461 \\
\hline ARM & $0.919 * * *$ & EGY & $0.590 *$ & KEN & $0.845^{* *}$ & PRT & 0.654 \\
\hline AUS & $0.635 *$ & ERI & -0.188 & KGZ & $0.724 * *$ & ROU & -0.466 \\
\hline AUT & 0.633 & ESP & $0.790 * *$ & KOR & $0.651^{*}$ & RUS & 0.657 * \\
\hline AZE & $0.916 * * *$ & ETH & $0.837 * *$ & LAO & $0.882 * *$ & RWA & 0.554 \\
\hline BDI & $0.896 * * *$ & FIN & $0.688^{* *}$ & LBR & -0.315 & SAU & $0.843 * * *$ \\
\hline BEN & $0.875 * * *$ & FJI & 0.360 & LKA & -0.0198 & SEN & $0.871 * * *$ \\
\hline BFA & $0.889 * * *$ & FRA & $0.747 * *$ & MAR & $0.662 *$ & SLE & 0.532 \\
\hline BGR & 0.509 & GAB & $0.890 * * *$ & MDG & 0.631 & SRB & $0.850 * *$ \\
\hline $\mathrm{BIH}$ & $0.674 *$ & GBR & 0.556 & MEX & $0.825 * * *$ & SUR & $0.927 * * *$ \\
\hline BLZ & $0.929 * * *$ & GEO & $0.879 * * *$ & MKD & 0.355 & SVK & -0.448 \\
\hline BOL & $0.815 * *$ & GEHE & $0.743 * *$ & MLI & $0.952 * * *$ & SWE & $0.694^{* *}$ \\
\hline BRA & $0.684 * *$ & GIN & $0.771 * *$ & MNE & $-0.755 *$ & TCD & 0.622 \\
\hline BWA & 0.266 & GNQ & 0.519 & MNG & 0.432 & TGO & 0.625 \\
\hline CAF & 0.221 & GRC & 0.357 & $\mathrm{MOZ}$ & $0.831 * * *$ & THA & $0.606 *$ \\
\hline CAN & 0.101 & GIM & $0.885 * * *$ & MRT & $0.873 * * *$ & TJK & -0.162 \\
\hline CHL & 0.544 & GUY & $0.619 *$ & MYS & $0.856 * * *$ & TUN & 0.409 \\
\hline $\mathrm{CHN}$ & $0.919 * * *$ & HND & $0.654 *$ & NAM & 0.261 & TUR & $0.917 * * *$ \\
\hline CIV & $0.603 *$ & HUN & -0.0190 & NER & $0.606 *$ & TZA & $0.804 * * *$ \\
\hline CMR & $0.830 * *$ & IDN & 0.108 & NGA & $0.870 * * *$ & UGA & $0.677 *$ \\
\hline COD & $0.900 * * *$ & IND & $0.631 *$ & NIC & $0.755 * *$ & UKR & $0.554 *$ \\
\hline $\mathrm{COG}$ & $0.834 * *$ & IRL & -0.0137 & NOR & $0.851 * * *$ & URY & 0.242 \\
\hline $\mathrm{COL}$ & 0.394 & IRN & $0.841 * * *$ & NZL & $0.796 * *$ & UZB & 0.327 \\
\hline CRI & -0.156 & IRQ & 0.413 & OMN & -0.446 & VEN & 0.450 \\
\hline CUB & 0.137 & ISR & -0.108 & PAK & $0.693^{* *}$ & VNM & $0.837 * * *$ \\
\hline CYP & -0.411 & ITA & $0.882 * * *$ & PAN & $0.886^{* *}$ & ZAF & $0.666 *$ \\
\hline DEU & 0.484 & JAM & $-0.596 *$ & PER & $0.720 * *$ & ZMB & $0.767 * *$ \\
\hline DNK & $-0.765^{*}$ & JOR & -0.149 & PHL & 0.416 & ZWE & -0.294 \\
\hline DZA & 0.468 & JPN & $0.624 \%$ & PNG & $0.577 *$ & & \\
\hline
\end{tabular}

We use ArcGIS to combine the various geo-coded datasets and to analyse the intensity and spatial distribution of light across mines, ethnic groups and countries. Specifically, we compute zonal statistics and merge mining facilities to ethnicities and ethnicities to countries according to their centre of area. Although this procedure also adds some noise to our estimates, it helps minimise the problem of endogenous boundaries mentioned above. Based on the results of the zonal statistics, we use Stata to compute GINI coefficients at the country level measuring the distribution of the sum of lights near mining facilities $r_{i}$ (to proxy for real mineral rents) across $N$ ethnic homelands $i=1, \ldots, n_{j}$ within single countries. In addition, we calculate GINIs for light per capita in the remaining area (to proxy for income) $l_{i}$ across the same ethnic homelands. If ethnic homelands are indexed in non-decreasing order $\left(r_{i+1} \geq r_{i}\right.$, resp. $l_{i+1} \geq l_{i}, \forall i=$ $\left.1, \ldots, n_{j}\right)$, the GINIs can be calculated as follows: 


$$
\begin{gathered}
\text { MineralGINI }=\frac{1}{n_{j}}\left(n_{j}+1-2 \cdot \frac{\sum_{i=1}^{n_{j}}\left(n_{j}+1-i\right) \cdot r_{i}}{\sum_{i=1}^{n_{j}} r_{i}}\right) \\
\text { IncomeGINI }=\frac{1}{n_{j}}\left(n_{j}+1-2 \cdot \frac{\sum_{i=1}^{n_{j}}\left(n_{j}+1-i\right) \cdot l_{i}}{\sum_{i=1}^{n_{j}} l_{i}}\right)
\end{gathered}
$$

For simplicity, we call these MineralGINI and IncomeGINI. Because it is not easy to see the difference between the measures from the formulas, we illustrate our approach in Figure 2.

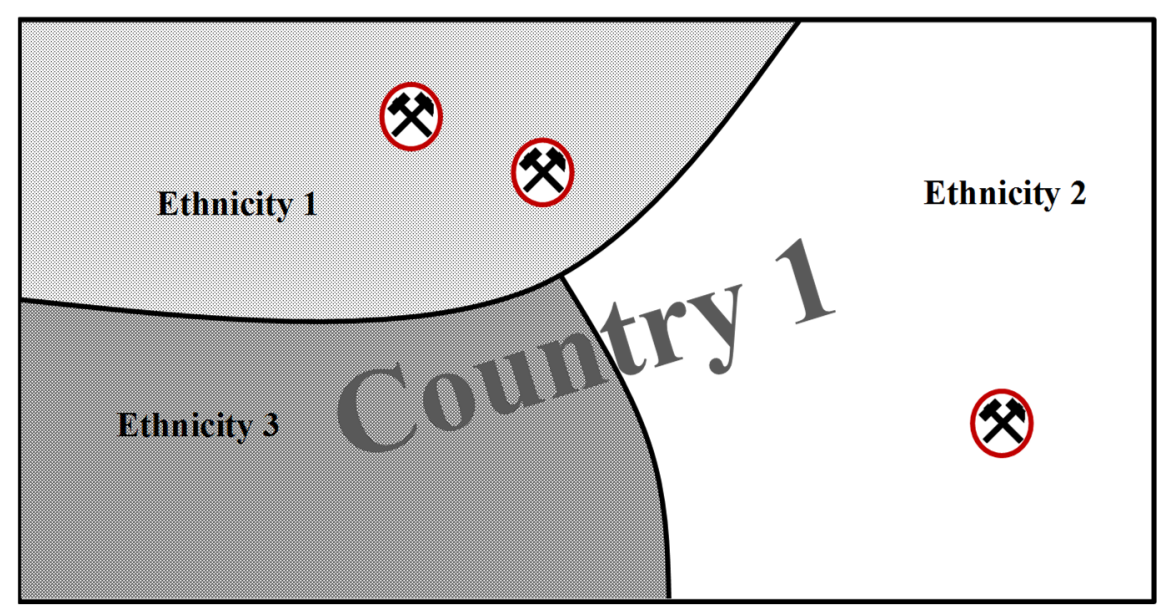

\section{Figure 2: Calculation of concentration measures.}

The figure shows a stylised country, which is inhabited by three different ethnic groups (light grey, grey, and white). There are also three mining facilities, which are, however, unequally distributed across ethnicities. The MineralGINI measures the concentration of the light emissions from the three mines (red circles) across the three ethnicities, where each ethnicity receives the same weight, i.e., we abstract from differences in group size. For the IncomeGINI, we consider the light density across ethnic groups, disregarding the light emitted from the mining facilities (within the red circles). This approach is similar to that of Alesina et al. (2016), except that we omit mining areas.

The results are illustrated in Figures 3 and 4. In particular, in Sub-Saharan Africa, we observe a close relationship between both indicators. The correlation is 0.81 in the Sub-Saharan sample and 0.68 for the entire world. The more unequal the distribution of mineral resource rents across ethnicities, the larger the ethnic income inequalities. This result is quite important, since it implies that ethnic income inequality is strongly affected by exogenous geographic factors, where we are particularly interested in natural resources. However, since countries are more or less ethnically divided and endowed with different numbers of mines and mine types, we do not focus on absolute levels in the following empirical analysis but on changes in levels. 


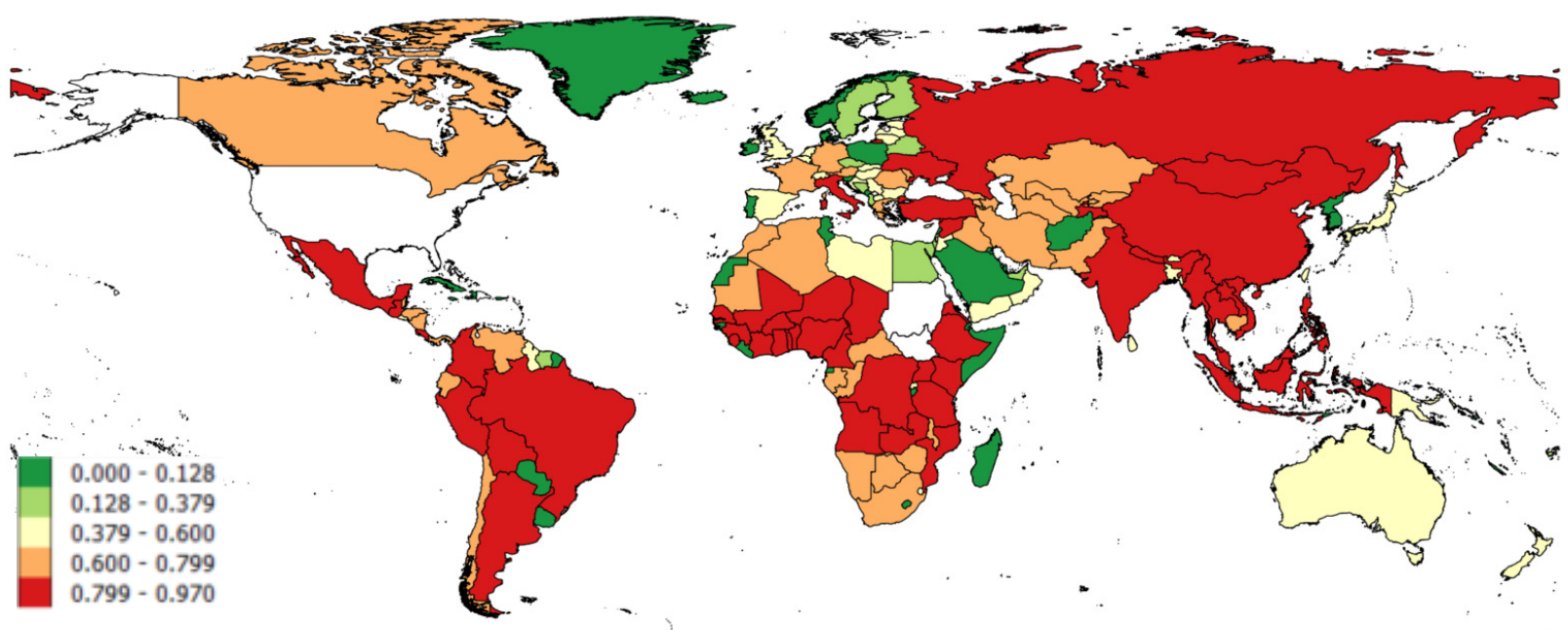

Figure 3: Average inequality in mine light across ethnic groups (MineralGINI)

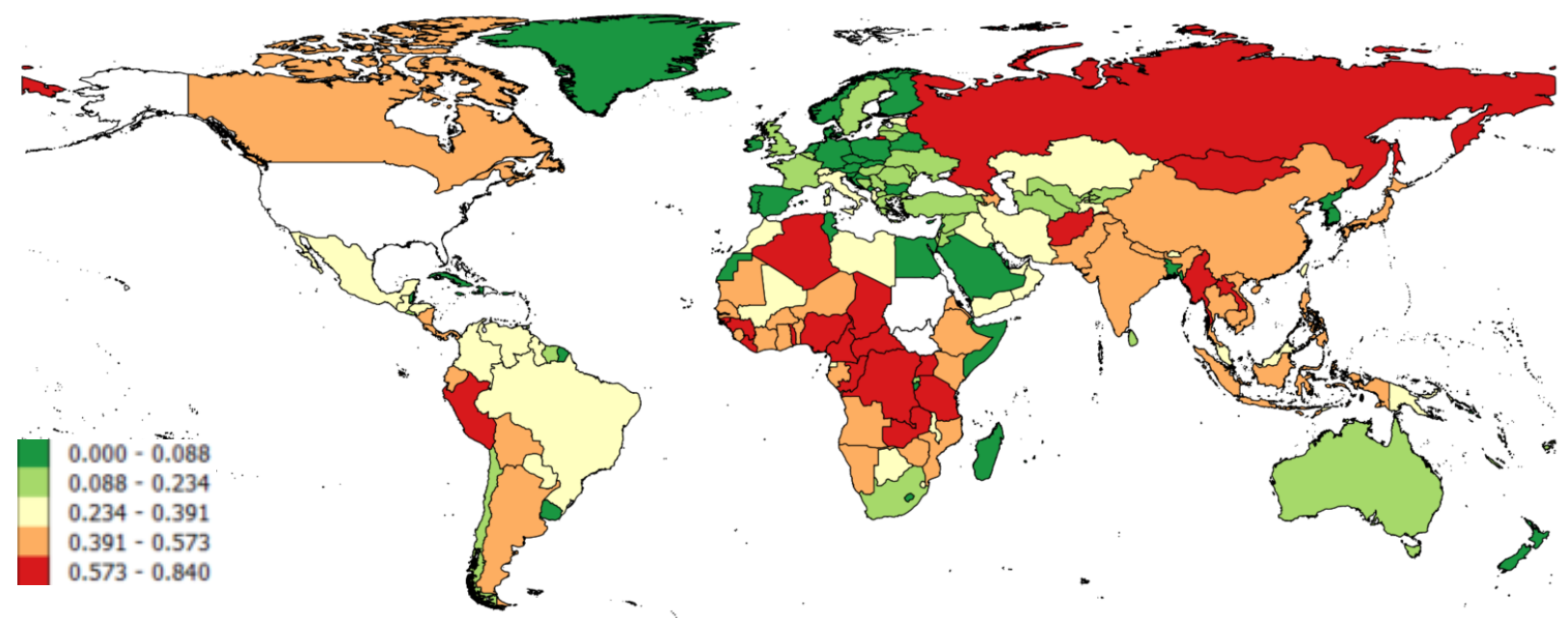

Figure 4: Average income inequality across ethnic groups (IncomeGINI)

Prior to the econometric analysis, let us critically discuss our resource measures. As mentioned above, one major advantage is that we can analyse the impact of natural resources on economic outcomes at the local level, which is impossible with existing country-level data. However, even if we abstract from this issue, mine light may be advantageous over resource revenues in monetary terms. If mining activities increase in a certain region, this creates jobs and income for the local population, regardless of whether a foreign company owns the mine. Changes in resource prices are unlikely to affect wages, at least as long as labour is abundant, which is likely to be the case for miners in particular in developing countries. However, long-term price shocks, which can be said to influence the local economy, are still captured because the mines' attractiveness either increases or decreases, as does the economic activity or nearby mines. Furthermore, using night-time lighting to measure resource inequality instead of monetary values 
such as resource rents helps to avoid endogeneity problems. Resource rents are mainly driven by the world price of the considered commodity. Therefore, there may be reverse causality between rents and war. On the one hand, increasing rents (e.g., windfalls due to price shocks in the world market) may cause higher resource inequality and, thus, lead to incentives to start an armed conflict. On the other hand, the literature on stock markets states that the market (over)reacts to news, especially when it is associated with rising prices (see, e.g., Shleifer and Summers 1990, Chan 2003, Vega 2006). It is reasonable to assume that the world market is rather efficient and anticipates the onset of conflicts in producing countries. Consequently, the market takes these risks into account a priori by raising the values of certain commodities. If this is the case, then world market prices, as used in some of existing studies, cannot be used as instruments for the intensity of resource extraction at the local level, since the exclusion restriction does not apply. On the contrary, night-time light emissions react inertially on changes in price levels or threats of conflicts, because their intensity depends on the local fixed capital - such as local lighting, facilities or the agglomeration of miners - which is less volatile than the price of (stock-) traded resources. Apart from this important issue, Dube and Vargas (2013) argue that the windfall effect of increasing rents on the probability of the onset of civil conflict is ambiguous.

Finally, let us briefly comment on additional data sources. The country-level boundaries are taken from the Global Administrative Areas (GADM) project version 2.7. It is a spatial database that contains location information for the administrative boundaries of countries and lowerlevel subdivisions all over the world. The Oak Ridge National Laboratory provides the LandScan population data. This data set contains information on geo-coded population densities on a 30 arc-second grid across the whole world. They attain this high resolution by disaggregating census counts on the basis of spatial data and satellite imagery. Using these population estimates, which are available on calendar year basis from 2000 to 2012, allows us to control for the number of people living close to mining facilities and in the surrounding ethnic homelands. In addition, we can at least partly capture polarisation effects, which are relevant in the context of rent seeking and conflict (see, e.g., Easterly and Levine 1997, Esteban and Ray 1999). Furthermore, we use the Uppsala Conflict Programme (UCDP) Monadic Conflict Onset and Incidence Dataset (Pettersson et al. 2016 and Gleditsch et al. 2002). This dataset contains information on intrastate conflicts and their year of onset. According to the UCDP definition, an onset of conflict is recorded if the use of armed forces in a new conflict occurs with at least 25 battle-related deaths or if more than one year has passed since the last observation of an already 
recorded conflict. The terrain data are distributed by the U.S. Geological Survey and the National Geospatial Intelligence Agency. The so-called Global Multi-resolution Terrain Elevation Data 2010 (GMTED 2010) include information on the average elevation of the Earth's surface within a 30 arc-second grid and replaces the often-used Global 30 Arc-Second Elevation (GTOPO30) dataset. As a measure of country-level ethnic fractionalisation, we use the fractionalisation index provided by Alesina et al. (2003). Other data that are used as covariates in our empirical analyses, such as Gross Domestic Product (GDP) or the size labour force are taken from the World Bank database.

\subsection{Estimation Results}

Based on the available data, we investigate the period between 2000 and 2012 to test the modelbased hypotheses. We present the results for each hypothesis separately.

\subsubsection{Mine light and ethnic income (H1)}

Hypothesis 1 states that a group, endowed with a certain resource, participates in growing rents more than other groups. To test this hypothesis, we estimate the following model using several specifications:

$$
\text { Lhome }_{i, j, t}=\alpha_{i}+\beta \cdot \text { Lmine }_{i, j, t}+\gamma \cdot \text { Lmine }_{-i, j, t}+\delta \cdot \text { Pop }_{i, j, t}+\tau_{t}+\theta_{\mathrm{t}}+\varepsilon_{i, j, t},
$$

where Lhome $_{i, j, t}\left(i=1,2, \ldots n_{j}, j=1,2, \ldots N, t=1,2, \ldots T\right)$ is the night-time light intensity of ethnicity $i$ in country $j$ at time $t ;{ }^{6}$ Lmine $_{i, j, t}$ is the total light intensity of nearby mining facilities in ethnicity $i$, Lmine $_{-i, j, t}$ denotes the light intensity at mining facilities in other ethnic homelands in the same country, $P o p_{i, j, t}$ is the population, $\tau_{t}$ are year fixed effects, $\theta_{t}$ are satellite configuration fixed effects, which change over time, and $\varepsilon_{i, j, t}$ is the error term. We use fixed effects and first differences estimation strategies to control for unobserved heterogeneity. Moreover, these strategies are inevitable because the calculation of Moran's I (for examples of spatial correlation see, e.g., Anselin 1995, Getis and Ord 1996 and Zhang et al. 2008) indicates the existence of spatial autocorrelation in night-time light between ethnic homelands and mining areas. ${ }^{7}$ Standard errors are clustered at the country level. The number of observations totals 16,983 and 15,576 . Specifically, we estimate equation (24) using 1,370 ethnicities ${ }^{8}$, which are

\footnotetext{
${ }^{6}$ The mining area was excluded before the light intensity of the remaining area of the ethnic homeland was calculated.

${ }^{7}$ Ethnic homelands themselves have an I of 0.27 ; if mining areas are included as separate entities, the I increases to 0.484 .

${ }^{8}$ Some ethnicities are counted more than once, since they are located in different countries.
} 
located in 173 countries. We are aware that including Lmine $_{i}$ and Lmine $_{-i}$ at the same time may bias the standard errors. Thus, we also present the results obtained by including those explanatory variables separately. The results of different specifications of equation (24) are reported in Table 2 (fixed effects) and Table C 1 (first differences in the appendix). In both tables, column (1) explains ethnic homeland lighting intensity simply by means of lighting intensities nearby mining facilities inside and outside the considered homeland. In column (2), we add population data, and in column (3), we add satellite configuration fixed effects. Columns (4) and (5) separately control for the inside and outside mining effects.

In all of our specifications, the coefficient on Lmine $_{i}$ is positive and statistically significant. The brighter a mining area, the brighter the ethnicity where the mine is located. Importantly, the lighting intensity near the mines of all other ethnicities $\left(\right.$ Lmine $\left._{-i}\right)$ have neither statistically significant nor economic relevant effects on the night-time lighting of the ethnic homeland itself.

Table 2: Fixed effects estimates of eq. (24)

Dependent variable: Light in ethnic homeland of group $i\left(\right.$ Lhome $\left._{i}\right)$

\begin{tabular}{|c|c|c|c|c|c|}
\hline & $(1)$ & (2) & (3) & (4) & (5) \\
\hline Lmine $_{i}$ & $\begin{array}{c}13.70^{* * *} \\
(5.30)\end{array}$ & $\begin{array}{c}12.73^{* * *} \\
(5.93)\end{array}$ & $\begin{array}{c}12.72^{* * *} \\
(5.85)\end{array}$ & $\begin{array}{c}12.72^{* * *} \\
(5.85)\end{array}$ & \\
\hline Lmine $_{-i}$ & $\begin{array}{c}0.0308 \\
(1.15)\end{array}$ & $\begin{array}{c}0.00452 \\
(0.27)\end{array}$ & $\begin{array}{c}0.0216 \\
(0.65)\end{array}$ & & $\begin{array}{c}-0.00177 \\
(-0.04)\end{array}$ \\
\hline Pop & & $\begin{array}{c}0.0542^{*} \\
(2.23)\end{array}$ & $\begin{array}{c}0.0555^{*} \\
(2.24)\end{array}$ & $\begin{array}{c}0.0555^{*} \\
(2.24)\end{array}$ & $\begin{array}{l}0.101^{*} \\
(2.01)\end{array}$ \\
\hline YearFE & NO & $\mathrm{NO}$ & YES & YES & YES \\
\hline SatelliteFE & NO & NO & YES & YES & YES \\
\hline Constant & $\begin{array}{c}-56895.1 \\
(-1.30)\end{array}$ & $\begin{array}{c}-256117.6^{*} \\
(-2.50)\end{array}$ & $\begin{array}{c}-244742.6^{*} \\
(-2.45)\end{array}$ & $\begin{array}{c}-239089.7^{*} \\
(-2.41)\end{array}$ & $\begin{array}{c}-189006.9 \\
(-0.92)\end{array}$ \\
\hline$R^{2}$ within & 0.4293 & 0.4588 & 0.4598 & 0.4598 & 0.1232 \\
\hline$R^{2}$ between & 0.1936 & 0.3167 & 0.3167 & 0.3167 & 0.2675 \\
\hline$R^{2}$ overall & 0.1978 & 0.3160 & 0.3160 & 0.3160 & 0.2621 \\
\hline \#Obs. & 16983 & 16983 & 16983 & 16983 & 16983 \\
\hline \# Groups & 1370 & 1370 & 1370 & 1370 & 1370 \\
\hline
\end{tabular}

However, there are still three problems that need to be addressed. First, it is questionable whether it is the ethnic homeland that benefits from resource extraction or if this is simply a 
spatial effect, that is, the cities and villages near the mine benefit from resources independently of their affiliation with a certain ethnicity. Second, although we use data on ethnic homelands that pre-date the active mining facilities data, these ethnic boundaries may still be endogenous to the mine locations because the mine itself or information on resource-abundant areas may be older than the boundary. Indeed, this might have contributed to the evolution of homelands in particular given that mines are usually located in mountainous areas which are natural borders of ethnic homelands. Third, our results may be driven be reverse causality since we cannot rule out that an increasing income in an ethnic homeland increases demand for their resource or enables the members of the ethnic group to use more advanced technologies, which facilitate higher extraction rates.

To tackle the first two problems, we compute the centre of area of each ethnic homeland and construct Thiessen polygons based on this information. Then, we repeat our estimation strategy assuming that these polygons are our new ethnic homelands. This procedure solves the mineboundary endogeneity issue because mines that were previously located close to boundaries are almost randomly assigned to ethnic homelands now. As already noted by Alesina et al. (2016), using Thiessen polygons helps distinguish the spatial effect from the ethnicity effect mentioned above. If our fixed effect estimates of equation (24) are robust to potential mine-boundary endogeneity and measure an ethnicity rather than a spatial effect, we expect that the coefficients of our Thiessen polygon estimation strategy to still be statistically significantly different from zero but lower than in the previous case. The results are reported in Table A 1 in the appendix. Comparing the Lmine $_{i}$ coefficients of both homeland definitions, it becomes obvious that there is a sizeable gap between them, although they are statistically significant and point in the same direction. Therefore, we are confident that our results measure an ethnicity effect and do not suffer from boundary issues.

To solve the third problem, we cannot apply an IV estimation strategy because the exclusion restriction does not apply if we use world prices as an instrument. The endogeneity of prices has two causes. First, as mentioned above, prices may be endogenous to conflicts because of market efficiency. Second, the production of some mines is a considerable share of overall worldwide production; e.g., the Escondida copper mine in Chile accounts for approximately 5 per cent of total production. Therefore, there is no unambiguous causal effect from price levels towards production. Since there are no other feasible instruments, we check whether Lhome or Lmine contain a unit root and test for Granger causality instead. The results are reported in 
Table B 1 and Table B 2 in the appendix. Based on the statistically significant lagged but insignificant lead variables, it becomes obvious that Lmine Granger causes Lhome. We also consider the reverse pattern, checking whether Lhome Granger causes Lmine, but the results show no Granger causality in this direction. Hence, there is no need to assume that our baseline outcomes are the result of reverse causality.

Based on the results and the additional robustness checks, we cannot reject hypothesis 1 . Therefore, we conclude that natural resources have a distinct positive effect on economic performance on the ethnic homeland level. Resource endowments are at least a blessing for nearby regions. Moreover, it is worth noting that the magnitude of the coefficients suggest that an unequal distribution of resources across ethnicities may contribute substantially to ethnic income inequality, what is subject to the following hypothesis. This may explain why resources could be a curse for nations.

\subsubsection{Inequality in resource endowments and ethnic inequality (H2)}

Next, we analyse whether income inequality increases as resource inequality rises. We use our light-based MineralGINI $I_{j, t}$ and IncomeGIN $I_{j, t}$ variables as proxies for real resource rents and income inequality in country $j=1, \ldots, N$ at time $t=1, \ldots, T$ and estimate different specifications of the following regression:

$$
\operatorname{IncomeGINI}_{j, t}=\alpha_{i}+\beta \cdot \text { MineralGINI } I_{j, t}+\log G D P_{j, t}+\psi_{j, t}+\tau_{t}+\theta_{\mathrm{t}}+\varepsilon_{j, t} .
$$

In addition to our time $\left(\tau_{t}\right)$ and satellite configuration $\left(\theta_{t}\right)$ fixed effects, we include a logarithmised income variable $\log G D P_{j, t}$ (GDP per capita in PPP, constant US\$) in first- and secondorder terms to control for income-induced inequality effects (see Kuznets 1955). ${ }^{9}$ Furthermore, we use a dummy variable $\psi_{i, t}$ to control for the existence of any active mining facility. ${ }^{10}$ As noted by Alesina et al. (2016), geographic conditions such as elevation, distance to the coast or temperature, which may be highly correlated with resource availability, are also important factors in the discussion of ethnic inequality. Therefore, we try to capture most of these effects by estimating different specification of equation (25) using a fixed effects estimation strategy. The results of the fixed effects model are shown in Table 3.

Interestingly, a simple regression of IncomeGINI on MineralGINI (see column (1)) explains approximately $44 \%$ of the variation in the data. Furthermore, the coefficient of MineralGINI is

\footnotetext{
${ }^{9}$ We report income as well as income category variables because the national boundaries that were applied in calculating the IncomeGINI do not perfectly fit the real world boundaries.

${ }^{10}$ Active is defined as the existence of lighting close to recorded mining facilities.
} 
significantly positive and economically relevant. Adding the active mining facility dummy variable in column (2) shows that our outcomes are to some extent in line with the results of Fum and Hodler (2010). The existence of resources per se comes with a lower degree of income inequality, whereas an unequal distribution of resources across ethnicities increases income inequality. Indeed, a MineralGINI of approximately 0.15 marks the split from a positive resource effect towards a negative. In columns (3) and (4), we also control for income effects, but the coefficient of MineralGINI does not change in an economically relevant order until we add the interaction terms in column (6). Indeed, the MineralGINI variable becomes relevant by strongly limiting the positive effect of income on inequality, whereas the constant increases by a factor of 1.5 in comparison to (3).

However, the following issues arise: First, one could argue that minerals only account for a small share of natural resources. Thus, we split our sample according to the share of oil rents of GDP. Observations with shares of less than $5 \%$ of oil rents are reported in column (6); the remaining observations, in column (7). It becomes obvious that the effect of MineralGINI is stronger in the subsample of comparatively oil-poor observations but still significant in the oilrich subsample.

Second, our MineralGINI variable also measures - besides the distribution of minerals across ethnicities - ethnic fractionalisation itself, because the number of ethnic homelands $N$ directly affects its level. In our empirical investigation, this is not a problem, since we focus on fixed effects models, where the number of ethnicities and mines within a country is taken as timeinvariant, while the variation in the luminosity of mines and ethnic groups is used to estimate the coefficients of interest. However, to ensure that our results are not depending on ethnic fractionalisation itself, we test the effect of an interaction between the MineralGINI and ethnic fractionalisation index - called Ethnic - in column (8). The effect of an unequal distribution of resources across ethnicities on ethnic income inequality is less pronounced in countries that are already highly fractionalised. Nevertheless, the coefficient of MineralGINI is significant positive and the marginal effect is in an economical relevant order as well as statistically significant even for highly fractionalized countries (see Figure D 3 in the appendix). To tackle the fractionalization issue more specifically, we also split our full sample at the median of the fractionalization index (0.484) and run equation (25) for both subsamples. The results for the ethnic homogeneous subsample are reported in column (9) and the heterogeneous subsample is reported in column (10). Interestingly, the coefficients of both subsamples do not differ in an economically relevant order and reveal the importance of the distribution of minerals across 
ethnic groups regardless of the level of ethnic fractionalization.

Third, to guard against possible border endogeneity problems and to verify that it is the distribution of mines across ethnicities that matters and not the spatial distribution itself, we use Thiessen polygons of ethnic homelands to perform additional robustness checks. In a first step, we analyse whether the resource distribution across Thiessen homelands contributes in explaining the income distribution across those. If border endogeneity is not an issue, we expect the coefficient of MineralGINI $I_{\text {Thiessen }}$ to be significant positive. Based on the results, which are reported in Table A 2, we are confident that our results are not biased by border endogeneity of mines. In a second step, we try to separate the mineral inequality effect across ethnic homelands from a simple spatial mineral inequality effect by considering both MineralGINIs - across ethnic homelands and across artificial Thiessen homelands - at the same time. The results are reported in Table A 3. Based on the distinct different effects of the mineral inequality figures, we cannot reject the hypothesis that income inequality grows as resource inequality across different ethnicities rises. Consequently, we state that, although the effect of natural resources is positive at the local level, their distribution across different ethnicities is a driving factor for income inequality, which may induce rent-seeking behaviour. 
Table 3: Fixed effects estimates of eq. (25)

\begin{tabular}{|c|c|c|c|c|c|c|c|c|c|c|}
\hline & \multicolumn{10}{|c|}{ Dependant variable: Ethnic income inequality (IncomeGINI) } \\
\hline & (1) & (2) & (3) & (4) & (5) & (6) & (7) & $(8)$ & (9) & $(10)$ \\
\hline MineralGINI & $\begin{array}{l}0.353^{* * *} \\
(15.24)\end{array}$ & $\begin{array}{l}0.367^{* * *} \\
(15.51)\end{array}$ & $\begin{array}{l}0.390^{* * *} \\
(15.89)\end{array}$ & $\begin{array}{l}0.389^{* * *} \\
(15.87)\end{array}$ & $\begin{array}{l}-0.024 \\
(-0.13)\end{array}$ & $\begin{array}{l}0.495^{* * *} \\
(12.52)\end{array}$ & $\begin{array}{l}0.390^{* * *} \\
(11.24)\end{array}$ & $\begin{array}{l}0.633^{* * *} \\
(14.31)\end{array}$ & $\begin{array}{l}0.601^{* * *} \\
(17.66)\end{array}$ & $\begin{array}{c}0.508^{* * *} \\
(9.28)\end{array}$ \\
\hline ActiveFacility & & $\begin{array}{c}-0.0571^{* *} \\
(-2.83)\end{array}$ & $\begin{array}{l}-0.049 \\
(-1.89)\end{array}$ & $\begin{array}{l}-0.049 \\
(-1.91)\end{array}$ & $\begin{array}{l}-0.037 \\
(-1.39)\end{array}$ & $\begin{array}{l}0.020 \\
(0.74)\end{array}$ & $\begin{array}{c}-0.325^{* * *} \\
(-5.00)\end{array}$ & $\begin{array}{l}0.022 \\
(0.80)\end{array}$ & $\begin{array}{l}0.006 \\
(0.15)\end{array}$ & $\begin{array}{l}0.007 \\
(0.17)\end{array}$ \\
\hline $\log G D P p C$ & & & $\begin{array}{c}-0.040^{* * *} \\
(-3.51)\end{array}$ & $\begin{array}{l}-0.241^{* *} \\
(-3.37)\end{array}$ & $\begin{array}{c}-0.065^{* * *} \\
(-4.13)\end{array}$ & & & & & \\
\hline $\log G D P p C^{2}$ & & & & $\begin{array}{c}0.011^{* *} \\
(2.85)\end{array}$ & & & & & & \\
\hline $\begin{array}{l}\log G D P p C \cdot \\
\text { MineralGINI }\end{array}$ & & & & & $\begin{array}{l}0.043^{*} \\
(2.13)\end{array}$ & & & & & \\
\hline $\begin{array}{l}\text { MineralGINI } \\
\cdot \text { Ethnic }\end{array}$ & & & & & & & & $\begin{array}{l}-0.222^{*} \\
(-2.15)\end{array}$ & & \\
\hline Constant & $\begin{array}{c}0.120^{* * *} \\
(9.68)\end{array}$ & $\begin{array}{c}0.164^{* * *} \\
(8.32)\end{array}$ & $\begin{array}{c}0.502^{* * *} \\
(4.84)\end{array}$ & $\begin{array}{c}1.375^{* * *} \\
(4.25)\end{array}$ & $\begin{array}{c}0.740^{* * *} \\
(5.07)\end{array}$ & $\begin{array}{l}0.023 \\
(0.74)\end{array}$ & $\begin{array}{c}0.435^{* * *} \\
(7.86)\end{array}$ & $\begin{array}{l}0.012 \\
(0.37)\end{array}$ & $\begin{array}{l}-0.081^{*} \\
(-2.09)\end{array}$ & $\begin{array}{l}0.105^{*} \\
(2.13)\end{array}$ \\
\hline$R^{2}$ within & 0.1300 & 0.1334 & 0.1523 & 0.1559 & 0.1547 & 0.1329 & 0.2340 & 0.2083 & 0.2777 & 0.1840 \\
\hline$R^{2}$ between & 0.4571 & 0.4924 & 0.5338 & 0.5455 & 0.5134 & 0.3821 & 0.4958 & 0.3223 & 0.5086 & 0.2747 \\
\hline$R^{2}$ overall & 0.4369 & 0.4707 & 0.5130 & 0.5242 & 0.4922 & 0.3565 & 0.5008 & 0.3148 & 0.4894 & 0.2667 \\
\hline \# Obs. & 2242 & 2242 & 2046 & 2046 & 2046 & 1609 & 556 & 1859 & 923 & 936 \\
\hline \# Groups & 173 & 173 & 159 & 159 & 159 & 134 & 53 & 143 & 71 & 72 \\
\hline
\end{tabular}

Note: All regressions include country and time fixed effects.

$t$ statistics in parentheses; ${ }^{*} p<0.05,{ }^{* *} p<0.01,{ }^{* * *} p<0.001$ 


\subsubsection{Mine lights, resource inequality and national development (H3)}

In addition to the deteriorating effect of resource inequality on income inequality, hypothesis 3 states that the distribution of resources across different (ethnic) groups is a driving factor of a society's economic performance. Although our model suggests that the effect strongly depends on the income elasticity of labour, we focus on the average effect and provide more detailed results in Appendix E. We refrain from analysing the effect of income elasticity itself because this has been extensively done in Hodler (2006), and our theoretical prediction is in line with his theoretical and empirical results.

Because light intensity is said to be a very good indicator of economic development, which is available from high-quality data all over the world, we estimate the following model: ${ }^{11}$

$$
\begin{aligned}
& \ln \left(L_{j, t}\right)=\alpha+\beta \cdot \ln \left(\text { LMine }_{j, t}\right)+\gamma \cdot \text { MineralGINI }_{j, t}+\delta \cdot \ln \left(\text { Pop }_{j, t}\right)+\eta_{j}+\psi_{j, t}+ \\
& \tau_{t}+\theta_{t}+\varepsilon_{j, t}
\end{aligned}
$$

where $L_{j, t}$ denotes the light intensity of country $j$ at time $t,{ }^{12} L M i n e_{j, t}$ is the total light intensity of mining facilities, ${ }^{13} \mathrm{Pop}_{j, t}$ is the total population, and $\eta_{j}$ denotes the income category according to World Bank definition. We analyse the relationship between resource inequality and economic performance (light) in terms of elasticities. This approach allows us to use the Henderson et al. (2012) GDP-light elasticity (approximately 0.3) to make a statement about the resource inequality effect on GDP in real terms.

Similarly to $H 2$, our theoretical model does not include other inequality measures that may have high potential for explaining cross-country differences in the occurrence of the resource curse (see Alesina et al. 2016). Thus, we also estimate equation (26) using a fixed effects estimation strategy to control for those and other unobserved heterogeneities. ${ }^{14}$ The results are shown in Table 4. Although the coefficient of MineralGINI is negative and statistically significant in column (1), it is insignificant in column (2) when we add the active mining facility dummy variable. These findings are quite intuitive because the existence of a mining facility is highly

\footnotetext{
${ }^{11}$ We use light intensity as a proxy of income for consistency reasons. If we use log(GDP p.c.) as dependent variable instead, our results are similar.

${ }^{12}$ Mining areas are excluded.

${ }^{13}$ We add +1 Digital Number to LMine before calculating the logarithm to avoid serious calculation problems.

${ }^{14}$ OLS results of equation (26) are reported in Table C2 in the appendix.
} 
correlated with the MineralGINI, since there is more than one ethnic homeland in most countries in the world. However, taking the MineralGINI coefficient in column (1) as well as the GDP-light elasticity into account, a change from a homogeneous resource distribution towards a fully heterogeneous one comes with declines in real GDP of more than $7 \%$, on average.

Table 4: Fixed effects estimates of eq. (26)

\begin{tabular}{|c|c|c|c|c|c|c|c|}
\hline & \multicolumn{7}{|c|}{ Dependant variable: National light intensity $(\ln (L))$} \\
\hline & $(1)$ & $(2)$ & $(3)$ & $(4)$ & $(5)$ & $(6)$ & $(7)$ \\
\hline $\ln ($ LMine $)$ & $\begin{array}{l}0.491^{* * *} \\
(28.25)\end{array}$ & $\begin{array}{l}0.618^{* * *} \\
(34.45)\end{array}$ & $\begin{array}{l}0.448^{* * *} \\
(23.47)\end{array}$ & $\begin{array}{c}0.581^{* * *} \\
(14.87)\end{array}$ & $\begin{array}{l}0.491^{* * *} \\
(26.77)\end{array}$ & $\begin{array}{c}0.392^{* * *} \\
(17.87)\end{array}$ & $\begin{array}{l}0.726^{* * *} \\
(21.84)\end{array}$ \\
\hline $\ln (P o p)$ & $\begin{array}{l}1.349^{* * *} \\
(21.07)\end{array}$ & $\begin{array}{l}1.204^{* * *} \\
(19.94)\end{array}$ & $\begin{array}{l}1.941^{* * *} \\
(21.30)\end{array}$ & $\begin{array}{c}0.811^{* * *} \\
(8.79)\end{array}$ & $\begin{array}{l}1.200^{* * *} \\
(18.59)\end{array}$ & $\begin{array}{l}1.806^{* * *} \\
(12.20)\end{array}$ & $\begin{array}{c}0.903^{* * *} \\
(12.88)\end{array}$ \\
\hline MineralGINI & $\begin{array}{c}-0.286^{* *} \\
(-2.71)\end{array}$ & $\begin{array}{l}-0.101 \\
(-1.02)\end{array}$ & $\begin{array}{c}-0.672^{* * *} \\
(-3.98)\end{array}$ & $\begin{array}{l}-0.169 \\
(-1.16)\end{array}$ & $\begin{array}{l}-0.417^{*} \\
(-2.22)\end{array}$ & $\begin{array}{c}-0.423^{* *} \\
(-2.67)\end{array}$ & $\begin{array}{l}-0.163 \\
(-0.79)\end{array}$ \\
\hline $\begin{array}{l}\text { MineralGINI } \\
\cdot \text { Ethnic }\end{array}$ & & & & & $\begin{array}{l}0.361 \\
(0.83)\end{array}$ & & \\
\hline $\begin{array}{l}\text { Active } \\
\text { Facility }\end{array}$ & & $\begin{array}{c}-1.890^{* * *} \\
(-16.64)\end{array}$ & & & & & \\
\hline Constant & $\begin{array}{l}-14.05^{* * *} \\
(-14.23)\end{array}$ & $\begin{array}{l}-11.34^{* * *} \\
(-12.11)\end{array}$ & $\begin{array}{c}-22.985^{* * *} \\
(-16.21)\end{array}$ & $\begin{array}{c}-6.214^{* * *} \\
(-4.46)\end{array}$ & $\begin{array}{c}-11.800^{* * *} \\
(-11.76)\end{array}$ & $\begin{array}{c}-20.232^{* * *} \\
(-8.65)\end{array}$ & $\begin{array}{c}-9.505^{* * *} \\
(-9.05)\end{array}$ \\
\hline$R^{2}$ within & 0.4886 & 0.5542 & 0.4971 & 0.5428 & 0.4712 & 0.4361 & 0.5517 \\
\hline$R^{2}$ between & 0.6189 & 0.6521 & 0.5903 & 0.7996 & 0.6072 & 0.6684 & 0.4861 \\
\hline$R^{2}$ overall & 0.6228 & 0.6558 & 0.5756 & 0.8138 & 0.6043 & 0.6625 & 0.4854 \\
\hline \#Obs. & 2046 & 2046 & 1585 & 461 & 1818 & 910 & 908 \\
\hline \# Groups & 159 & 159 & 129 & 43 & 141 & 70 & 71 \\
\hline
\end{tabular}

If we split the sample according to the oil rents threshold mentioned in $H 2$, we find that the effect of an unequal resource distribution is most pronounced in the oil-poor subsample (3). Indeed, in this subsample, MineralGINI explains differences in GDP of up to $15 \%$, whereas it is insignificant in the oil-rich subsample (4). Considering the fractionalisation effect in column (5) by including the interaction term as in $\mathrm{H} 2$, we find that the MineralGINI coefficient is negative but the marginal effect is weak and turns insignificant in highly fractionalised countries (see Figure D 4). Moreover, if we split the sample at median of the ethnic fractionalization index, we find a statistically significant negative coefficient for MineralGINI in the homogeneous subsample in column (6) and a negative but not statistically significant coefficient in the 
heterogeneous subsample in column (7).Since the Thiessen polygons provide similar outcomes (see Table A 4) and reveal the importance of the distribution of mines across ethnicities (see Table A 5), we are confident that resource inequality matters in an economic relevant order in the discussion on economic performance. Based on these findings and the detailed insights in the appendix, we cannot reject hypothesis 3 . In addition, the statistically significant positive coefficient of $L M i n e_{j, t}$ again reveals the per se positive effect of resources on economic performance which is undermined by their unequal distribution across different groups.

\subsubsection{Resource inequality and internal conflict (H4)}

Hypothesis 4 states that a heterogeneous resource distribution increases the probability of the onset of civil war. Similarly to $H 3$, we focus on the average effect and provide more detailed insights in Appendix E. To put this statement to the test, we estimate linear probability ${ }^{15}$, probit and logit regressions of the following model: ${ }^{16}$

$$
\text { Conflict }_{j, t}=\alpha+\beta \cdot \text { MineralGINI } I_{j, t}+\text { Rough }_{j}+\psi_{j, t}+\tau_{t}+\theta_{\mathrm{t}}+\varepsilon_{j, t},
$$

where Conflict $_{j, t}$ is a dummy variable, which denotes whether an armed intra-state conflict began in country $j=1, \ldots, J$ in year $t=1, \ldots, T .{ }^{17}$ Since we cannot use a fixed effects estimation strategy, we add a measure of roughness, $R o u g h_{j}$, to control for the terrain of a country because it might be highly correlated with our MineralGINI and is said to be a major driving factor of armed conflicts (see Fearon and Laitin 2003, 2011). However, we use neither the terrain ruggedness devised by Riley et al. (1999) nor the share of mountainous terrain in the country overall as do Fearon and Laitin (2003). Instead, we control for the average altitude of a

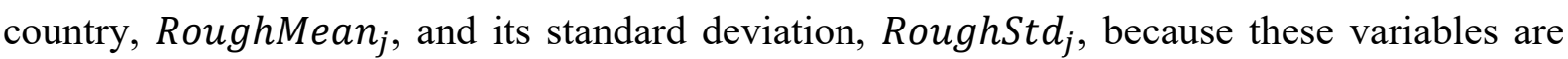
better controls in discussions on the resource curse. In the case of probit and logit regressions, we report the Average Partial Effects (APE) because they yield better insights than simple coefficients. The results of all strategies can be seen in Table 5. In columns (1) to (4) we report LPM results; in columns, (5)-(8) logit; and in (9)-(13), probit. We control for the existence of an active mining facility, for roughness and for stepwise income category fixed effects. Since

\footnotetext{
${ }^{15}$ Since LPMs come with heteroscedasticity, we report robust standard errors.

${ }^{16}$ One could argue that we lack causality because of an endogenous relation between our conflict measure and our MineralGINI. In fact, we agree that conflicts and resource rents are endogenous. However, since we use "light rents" instead of real resource rents, as well as the fact that we do not focus on total rents but on their spatial distribution, we are confident that our model is highly exogenous.

${ }^{17}$ According to the Armed Conflict Dataset, an onset is recorded if there is a new conflict or if there has been more than one year since the last observation of the conflict (see Gleditsch et al. 2002, Petterssen and Wallensteen 2016).
} 
there were no conflicts in the high-income category during our study period, the number of observations decreases slightly in the last columns. Based on the statistically significant effect of MineralGINI, it becomes obvious that a change from a totally homogeneous towards a totally heterogeneous distribution of real resource rents is associated with an increase in the probability of the onset of civil war of approximately 7 per cent. This result is robust to the inclusion of variables controlling for a country's terrain.

Furthermore, our result is almost independent of the estimation strategy and holds for both oil-poor and oil-rich - subsamples, as shown in Table C 3. In Table C 4, we again control for fractionalisation. To evaluate the interaction effect between MineralGINI and Ethnic in the non-linear probit and logit models, we rely on the inteff Stata command provided by Norton et al. (2004). However, neither the magnitude and nor the significance of MineralGINI coefficient is strongly affected by including a fractionalisation figure or an interaction term. In Table C 5, we split the sample at the fractionalisation median and report the results of the homogeneous subsample in the first column of each estimation strategy. Again, we find that the distribution of minerals is an important variable in both subsamples. As an additional robustness check, we use Thiessen homelands. Even after applying these different boundaries, higher inequality in resource endowments is associated with a higher risk of intrastate conflict onset (see Table A 6). Therefore, the estimates reveal the importance of the resource distribution across ethnicities in the discussion of the resource curse and its transmission channels. Note that we are not able to separate the effects of mineral inequality across ethnic homelands from a spatial mineral inequality effect, since we cannot include fixed effects in our regressions. Including both variables simultaneously does not yield any meaningful coefficient, since they are highly correlated in levels. 
Table 5: Estimates of eq. (27)

\begin{tabular}{|c|c|c|c|c|c|c|c|c|c|}
\hline & \multicolumn{9}{|c|}{ Dependant variable: Onset of armed conflict (Conflict) } \\
\hline & (1) & $\begin{array}{l}\text { LPM } \\
(2)\end{array}$ & (3) & (4) & $\begin{array}{l}\text { Logit } \\
(5)\end{array}$ & (6) & $(7)$ & $\begin{array}{c}\text { Probit } \\
(8)\end{array}$ & (9) \\
\hline $\begin{array}{l}\text { Mineral } \\
\text { GINI }\end{array}$ & $\begin{array}{c}0.054^{* * *} \\
(4.80)\end{array}$ & $\begin{array}{c}0.061^{* * *} \\
(5.18)\end{array}$ & $\begin{array}{c}0.054^{* * *} \\
(4.22)\end{array}$ & $\begin{array}{c}0.070^{* * *} \\
(3.98)\end{array}$ & $\begin{array}{c}0.083^{* * *} \\
(4.02)\end{array}$ & $\begin{array}{c}0.077^{* * *} \\
(3.67)\end{array}$ & $\begin{array}{c}0.064^{* * *} \\
(4.17)\end{array}$ & $\begin{array}{c}0.076^{* * *} \\
(4.24)\end{array}$ & $\begin{array}{c}0.070^{* * *} \\
(3.83)\end{array}$ \\
\hline $\begin{array}{l}\text { Active } \\
\text { Facility }\end{array}$ & & $\begin{array}{l}-0.023 \\
(-1.64)\end{array}$ & $\begin{array}{l}-0.020 \\
(-1.40)\end{array}$ & & $\begin{array}{l}-0.042 \\
(-1.71)\end{array}$ & $\begin{array}{l}-0.039 \\
(-1.59)\end{array}$ & & $\begin{array}{l}-0.038 \\
(-1.72)\end{array}$ & $\begin{array}{l}-0.035 \\
(-1.58)\end{array}$ \\
\hline $\begin{array}{l}\text { Rough } \\
\text { Mean }\end{array}$ & & & $\begin{array}{c}-0.00001 \\
(-1.00)\end{array}$ & & & $\begin{array}{c}-0.00001 \\
(-0.84)\end{array}$ & & & $\begin{array}{c}-0.00001 \\
(-0.72)\end{array}$ \\
\hline $\begin{array}{l}\text { Rough } \\
\text { Std }\end{array}$ & & & $\begin{array}{c}0.00004 \\
(1.49)\end{array}$ & & & $\begin{array}{c}0.00002 \\
(1.55)\end{array}$ & & & $\begin{array}{c}0.00002 \\
(1.56)\end{array}$ \\
\hline Constant & $\begin{array}{l}0.031 \\
(0.97)\end{array}$ & $\begin{array}{l}0.049^{*} \\
(2.12)\end{array}$ & $\begin{array}{l}0.043 \\
(1.82)\end{array}$ & $\begin{array}{c}0.034^{* * *} \\
(8.66)\end{array}$ & $\begin{array}{c}0.034^{* * *} \\
(8.67)\end{array}$ & $\begin{array}{c}0.034^{* * *} \\
(8.68)\end{array}$ & $\begin{array}{c}0.034^{* * *} \\
(8.65)\end{array}$ & $\begin{array}{c}0.034^{* * *} \\
(8.65)\end{array}$ & $\begin{array}{c}0.034^{* * *} \\
(8.67)\end{array}$ \\
\hline$($ Pseudo $) R^{2}$ & 0.0167 & 0.0163 & 0.0196 & 0.0623 & 0.0665 & 0.0708 & 0.0607 & 0.0651 & 0.0698 \\
\hline \# Obs. & 2063 & 2063 & 2063 & 2063 & 2063 & 2063 & 2063 & 2063 & 2063 \\
\hline
\end{tabular}

$t$ statistics in parentheses

${ }^{*} p<0.05,{ }^{* *} p<0.01,{ }^{* * *} p<0.001$ 


\section{Conclusions}

The vast majority of papers on the curse of natural resources are concerned with country-level data. Natural resources are said to harm national development, particularly if there is some degree of heterogeneity within countries, such as ethnic fractionalisation. However, most variation in the data does not come from differences in average resource endowments between countries but rather from the regional level within countries. Therefore, we study the curse of natural resources using data geo-coded at the regional level, which helps us identify the transmission channel through which resources contribute to underdevelopment.

Specifically, we investigate whether the spatial distribution of natural resources across different ethnic groups within countries impedes spatial inequalities, the incidence of armed conflict, and national economic performance. We introduce a rent-seeking model that extends the perspective of Hodler's (2006) common-pool model to a group-unique resource stock approach. Based on this new theoretical rent-seeking model, the following hypotheses regarding the distribution of resources across different ethnicities become obvious: (H1) A group, endowed with a certain resource, participates in growing rents more than other groups; (H2) Income inequality increases as resource inequality rises; (H3) An unequal distribution of resources is associated with low productivity, on average. Therefore, the distribution of resources across different groups is a driving factor of a society's economic performance; (H4) A heterogeneous resource distribution increases the probability of the onset of civil war for a broad range of elasticities $\alpha$.

We test our hypothesis empirically using geo-coded satellite night light, ethnic group, and mining facility data. We aim to measure the intensity of the resource extraction at the local level by focusing on mine lights. Moreover, mine lights are used to calculate a Gini index, which measures resource endowment inequality across ethnic groups. We find that the luminosity of a particular ethnic group whose ethnic homeland is endowed with a mining facility gains from the increased luminosity of the mine itself, while neighbouring ethnicities are unaffected $(\mathrm{H} 1)$. Moreover, the greater the inequality in the resource endowment within a country, the larger the ethnic income inequalities (H2). Considering the effects at the national level, we find that the luminosity of a country is negatively affected by the inequality of the resource endowment $(\mathrm{H} 3)$. Importantly, resources themselves spur regional and national development if they a distributed homogeneously, but unequal resource distribution is a curse for nations. Moreover, heterogeneous resource distribution is positively correlated with the probability of the onset of a civil 
war (H4). Based on our empirical approach, none of the above-mentioned hypotheses can be rejected.

We draw the following conclusions. The distribution of natural resources across different ethnicities is a major driving factor in spatial inequality and, thus, induces rent-seeking behaviour. As a consequence, rent seeking can be seen as a transmission channel from resource abundance to poor economic performance and to the onset of civil war. We find that natural resources do not harm economic development per se, while an unequal distribution of resources induces ethnic income inequality and underdevelopment. We therefore conclude that resources are a blessing for resource rich regions, but a curse for ethnically divided nations.

What can be done about it? Recent studies in the field of economic development and natural resources point out that institutional quality may contribute substantially in turning a resource curse into a blessing even at national level (see e.g. Mehlum et al. 2006a, Mehlum et al. 2006b, Robinson et al. 2006, Brunnschweiler 2008, Buonanno et al. 2015). As another factor, federalism tends to support the positive effect of democracy, increases investments in human capital, underpins property rights and, thus, leads to accelerated economic growth (see e.g. Weingast 1995, Brueckner 2006, Hatfield 2015, Adefeso and Abioro 2016). Considering the weak spatial match of ethnic homelands and administrative boundaries in most resource rich African countries, we suppose that a high degree of institutional quality and an ethnic-homeland-consistent federalism may be a cure for the resource curse (Farzanegan et al. 2013). However, this needs to be investigated in further studies.

At this point, it has to be mentioned that our analysis focuses on the spatial distribution of nonrenewable point resources across ethnicities. As a consequence, the theoretical and empirical results may look different if one considers renewable resources such as forest rents, soil quality heterogeneity or large oil and gas fields instead. ${ }^{18}$

\footnotetext{
${ }^{18}$ See Woods (2003), Nunn and Qian (2011) and Morelli and Rohner (2013) as examples for different types of resources and their effects on economic outcomes.
} 


\section{References}

Adefeso, H. A., \& Abioro, T. A. (2016). Fiscal decentralisation and economic development in Nigeria: The role of democratic institutions. Journal of Politics and Law, 9(1).

Alesina, A., Devleeschauwer, A., Easterly, W., Kurlat, S., \& Wacziarg, R. (2003). Fractionalization. Journal of Economic Growth, 8(2), 155-194.

Alesina, A., Michalopoulos, S., \& Papaioannou, E. (2016). Ethnic inequality. Journal of Political Economy, 124(2), 428-488.

Anselin, L. (1995). Local indicators of spatial association-LISA. Geographical analysis, 27(2), 93-115.

Aragón, F. M., \& Rud, J. P. (2013). Natural resources and local communities: evidence from a Peruvian gold mine. American Economic Journal: Economic Policy, 5(2), 1-25.

Arezki, R., Bhattacharyya, S., \& Mamo, N. (2015). Resource discovery and conflict in Africa: What do the data show? (No. 2015-14). Centre for the Study of African Economies, University of Oxford.

Berman, N., Couttenier, M., Rohner, D., \& Thoenig, M. (2015). This mine is mine! How minerals fuel conflicts in Africa, American Economic Review (forthcoming)

Bruno, M., \& Sachs, J. (1982). Energy and resource allocation: A dynamic model of the "Dutch Disease". Review of Economic Studies, 49(5), 845-859.

Brueckner, J. K. (2006). Fiscal federalism and economic growth. Journal of Public Economics, 90(10), 2107-2120.

Brunnschweiler, C. N. (2008). Cursing the blessings? Natural resource abundance, institutions, and economic growth. World Development, 36(3), 399-419.

Brunnschweiler, C. N., \& Bulte, E. H. (2009). Natural resources and violent conflict: resource abundance, dependence, and the onset of civil wars. Oxford Economic Papers, 61(4), 651-674.

Buonanno, P., Durante, R., Prarolo, G., \& Vanin, P. (2015). Poor institutions, rich mines: Resource curse in the origins of the Sicilian mafia. Economic Journal, 125(586), 175-202.

Chan, W. S. (2003). Stock price reaction to news and no-news: drift and reversal after headlines. Journal of Financial Economics, 70(2), 223-260.

Chen, X., \& Nordhaus, W. D. (2011). Using luminosity data as a proxy for economic statistics. Proceedings of the National Academy of Sciences, 108(21), 8589-8594.

Collier, P., \& Hoeffler, A. (1998). On economic causes of civil war. Oxford Economic Papers, 50(4), 563-573.

Collier, P., \& Hoeffler, A. (2004). Greed and grievance in civil war. Oxford Economic Papers, 56(4), 563-595.

Collier, P., \& Hoeffler, A. (2005). Resource rents, governance, and conflict. Journal of Conflict Resolution, 49(4), 625-633.

Corden, W. M., \& Neary, J. P. (1982). Booming sector and de-industrialisation in a small open economy. Economic Journal, 92(368), 825-848. 
Dube, O., \& Vargas, J. F. (2013). Commodity price shocks and civil conflict: Evidence from Colombia. Review of Economic Studies, 80(4), 1384-1421.

Esteban, J., \& Ray, D. (1999). Conflict and distribution. Journal of Economic Theory, 87(2), $379-415$.

Elvidge, C. D., Baugh, K. E., Kihn, E. A., Kroehl, H. W., Davis, E. R., \& Davis, C. W. (1997). Relation between satellite observed visible-near infrared emissions, population, economic activity and electric power consumption. International Journal of Remote Sensing, 18(6), 13731379.

Farzanegan, M. D., Lessmann C. \& Markwardt, G. (2013). Natural-Resource Rents and Internal Conflicts - Can Decentralization Lift the Curse?," CESifo Working Paper Series 4180, CESifo Group Munich.

Fearon, J. D., \& Laitin, D. D. (2003). Ethnicity, insurgency, and civil war. American Political Science Review, 97(01), 75-90.

Fearon, J. D., \& Laitin, D. D. (2011). Sons of the soil, migrants, and civil war. World Development, 39(2), 199-211.

Fum, R. M., \& Hodler, R. (2010). Natural resources and income inequality: The role of ethnic divisions. Economics Letters, 107(3), 360-363.

Gerlagh, R. \& Papyrakis, E. (2004). The resource curse hypothesis and its transmission channels. Journal of Comparative Economics, 32(1), 181-193.

Getis, A., \& Ord, J. K. (1996). Local spatial statistics: an overview. Spatial analysis: modelling in a GIS environment, 374.

Gleditsch, N. P., Wallensteen, P., Eriksson, M., Sollenberg, M., \& Strand, H. (2002). Armed conflict 1946-2001: A new dataset. Journal of peace research, 39(5), 615-637.

Han, Y. F., Sun, G. N., \& Li, Q. (2007). Mutually-inverse relationship between resource contribution and resource curse in economic development: A case study in 31 provinces of China [J]. Resources Science.

Hartwig, J. (2010). Is health capital formation good for long-term economic growth?-Panel Granger-causality evidence for OECD countries. Journal of Macroeconomics, 32(1), 314-325.

Hatfield, J. W. (2015). Federalism, taxation, and economic growth. Journal of Urban Economics, 87, 114-125.

Henderson, J. V., Storeygard, A., \& Weil, D. N. (2012). Measuring economic growth from outer space. American Economic Review, 102(2), 994-1028.

Herb, M. (2005). No representation without taxation? Rents, development, and democracy. Comparative Politics, 297-316.

Hodler, R. (2006). The curse of natural resources in fractionalized countries. European Economic Review, 50(6), 1367-1386.

Konrad, K. A., Olsen, T. E., \& Schöb, R. (1994). Resource extraction and the threat of possible expropriation: the role of Swiss bank accounts. Journal of Environmental Economics and Management, 26(2), 149-162. 
Kuznets, S. (1955). Economic growth and income inequality. American Economic Review, 45(1), 1-28.

Lane, P. R., \& Tornell, A. (1996). Power, growth, and the voracity effect. Journal of Economic Growth, 1(2), 213-241.

Lane, P. R. \& Tornell, A., (1999). The voracity effect. American Economic Review, 22-46.

Lessmann, C., \& Seidel, A. (2017). Regional inequality, convergence, and its determinants - A view from outer space. European Economic Review 92, 110-132.

Mankiw, G. D., Romer, D., \& Weil, D. N. (1992). A contribution to the empirics of economic growth. Quarterly Journal of Economics, 107(2), 407-437.

Mehlum, H., Moene, K., \& Torvik, R. (2006a). Institutions and the resource curse. Economic Journal, 116(508), 1-20.

Mehlum, H., Moene, K., \& Torvik, R. (2006b). Cursed by resources or institutions? World Economy, 29(8), 1117-1131.

Mehlum, H., Moene, K., \& Torvik, R. (2012). Mineral rents and social development in Norway. Mineral Rents and the Financing of Social Policy, 155-184.

Morelli, M., \& Rohner, D. (2015). Resource concentration and civil wars. Journal of Development Economics, 117, 32-47.

Munasib, A., \& Rickman, D. S. (2015). Regional economic impacts of the shale gas and tight oil boom: A synthetic control analysis. Regional Science and Urban Economics, 50, 1-17.

Nickell, S. (1981). Biases in dynamic models with fixed effects. Econometrica: Journal of the Econometric Society, 1417-1426.

Norton, E. C., Wang, H., \& Ai, C. (2004). Computing interaction effects and standard errors in logit and probit models. Stata Journal, 4(2), 154-167.

Nunn, N. \& Qian, N. (2011). The potato's contribution to population and urbanization: Evidence from a historical experiment. Quarterly Journal of Economics, 126, 593-650.

Pettersson, T. \& Peter Wallensteen (2016). Armed conflicts, 1946-2015. Journal of Peace Research, 53(5).

Riley, S. J., DeGloria, S. D., \& Elliot, R. (1999). A terrain ruggedness index that quantifies topographic heterogeneity. Intermountain Journal of Sciences, 5(1-4), 23-27.

Robinson, J. A., Torvik, R., \& Verdier, T. (2006). Political foundations of the resource curse. Journal of Development Economics, 79(2), 447-468.

Rohner, D., Thoenig, M., \& Zilibotti, F. (2013). War signals: A theory of trade, trust, and conflict. Review of Economic Studies, 80(3), 1114-1147.

Ross, M. L. (2001). Timber booms and institutional breakdown in Southeast Asia. Cambridge University Press.

Sachs, J. D., \& Warner, A. M. (1995, 1997). Natural resource abundance and economic growth (Working Paper No. w5398). National Bureau of Economic Research. 
Sachs, J. D., \& Warner, A. M. (2001). Natural resources and economic development: The curse of natural resources. European Economic Review, 45, 827-838.

Sala-i-Martin, X., \& Subramanian, A. (2013). Addressing the natural resource curse: an illustration from Nigeria. Journal of African Economies, 22(4), 570-615.

Shleifer, A., \& Summers, L. H. (1990). The noise trader approach to finance. Journal of Economic Perspectives, 4(2), 19-33.

Stijns, J. P. C. (2005). Natural resource abundance and economic growth revisited. Resources policy, 30(2), 107-130.

Usui, N. (1997). Dutch disease and policy adjustments to the oil boom: a comparative study of Indonesia and Mexico. Resources Policy, 23(4), 151-162.

Van Der Ploeg, F., \& Poelhekke, S. (2016). The impact of natural resources: Survey of recent quantitative evidence. Journal of Development Studies, 1-12.

Vega, C. (2006). Stock price reaction to public and private information. Journal of Financial Economics, 82(1), 103-133.

Weidmann, N. B., Rød, J. K., \& Cederman, L. E. (2010). Representing ethnic groups in space: A new dataset. Journal of Peace Research, 47(4), 491-499.

Weingast, B. R. (1995). The economic role of political institutions: Market-preserving federalism and economic development. Journal of Law, Economics, \& Organization, 1-31.

Wheeler, D. (1984). Sources of stagnation in sub-Saharan Africa. World Development, 12(1), $1-23$.

Woods, D. (2003). The tragedy of the cocoa pod: rent-seeking, land and ethnic conflict in Ivory Coast. Journal of Modern African Studies, 41(04), 641-655.

Wu, J., Wang, Z., Li, W., \& Peng, J. (2013). Exploring factors affecting the relationship between light consumption and GDP based on DMSP/OLS nighttime satellite imagery. Remote Sensing of Environment, 134, 111-119.

Zhang, C., Luo, L., Xu, W., \& Ledwith, V. (2008). Use of local Moran's I and GIS to identify pollution hotspots of $\mathrm{Pb}$ in urban soils of Galway, Ireland. Science of the total environment, $398(1), 212-221$. 


\section{Appendix}

\section{A Thiessen Polygons}

Table A 1: Fixed effects estimates of eq. (24) using Thiessen homelands ${ }^{19}$

\begin{tabular}{lccccc}
\hline Lhome $_{i,}$ & $(1)$ & $(2)$ & $(3)$ & $(4)$ & $(5)$ \\
\hline Lmine $_{i}$ & $0.825^{* *}$ & $0.802^{* *}$ & $0.776^{* *}$ & $0.812^{* *}$ & \\
& $(3.44)$ & $(3.48)$ & $(3.31)$ & $(3.53)$ & \\
& & & & \\
Lmine $_{-i}$ & $0.061^{* * *}$ & $0.059^{* * *}$ & $0.050^{* *}$ & & $0.057^{* *}$ \\
& $(3.66)$ & $(3.88)$ & $(3.32)$ & & $(3.38)$ \\
Pop & & & & & \\
& & $0.042^{*}$ & $0.041^{*}$ & 0.039 & 0.041 \\
& & $(2.09)$ & $(1.98)$ & $(1.91)$ & $(1.89)$ \\
YearFE & $\mathrm{NO}$ & $\mathrm{NO}$ & $\mathrm{YES}$ & $\mathrm{YES}$ & YES \\
SatelliteFE & $\mathrm{NO}$ & $\mathrm{NO}$ & $\mathrm{YES}$ & $\mathrm{YES}$ & $\mathrm{YES}$ \\
& & & & & \\
Constant & 3085.6 & -113089.9 & -89578.6 & -17999.8 & -53161.95 \\
& $(0.12)$ & $(-1.61)$ & $(-1.19)$ & $(-0.28)$ & $(-0.71)$ \\
$R^{2}$ within & & & & & \\
$R^{2}$ between & 0.1233 & 0.1657 & 0.1705 & 0.1531 & 0.1202 \\
$R^{2}$ overall & 0.0458 & 0.2926 & 0.2935 & 0.2812 & 0.2809 \\
\# Obs. & 20882 & 20882 & 20882 & 20882 & 20882 \\
\# Groups & 1726 & 1726 & 1726 & 1726 & 1726 \\
\hline
\end{tabular}

$t$ statistics in parentheses

${ }^{*} p<0.05,{ }^{* *} p<0.01,{ }^{* * *} p<0.001$

Table A 2: Fixed effects estimates of eq. (25) using Thiessen homelands

\begin{tabular}{lcc}
\hline IncomeGINI $_{\text {Thiessen }}$ & $(1)$ & $(2)$ \\
\hline MineralGINI $_{\text {Thiessen }}$ & $0.448^{* * *}$ & $0.448^{* * *}$ \\
& $(17.89)$ & $(17.88)$ \\
& & \\
ActiveFacility $_{\text {Thiessen }}$ & & 0.004 \\
& & $(0.08)$ \\
Constant & $0.030^{*}$ & 0.026 \\
& $(2.19)$ & $(0.54)$ \\
$R^{2}$ within & & \\
$R^{2}$ between & 0.1611 & 0.1611 \\
$R^{2}$ overall & 0.5368 & 0.5360 \\
\# Obs. & 0.5083 & 0.5076 \\
\# Groups & 2008 & 2008 \\
\end{tabular}

$t$ statistics in parentheses

${ }^{*} p<0.05,{ }^{* *} p<0.01,{ }^{* * *} p<0.001$

\footnotetext{
${ }^{19}$ In our original estimation in Table 2, we drop all countries smaller than $1.000 \mathrm{~km}^{2}$ and ethnicities with less than 10.000 inhabitants; for consistency, reason we now drop all Thiessen homelands with less than 10.000 inhabitants and light intensities of less than $100 \mathrm{DN}$. However, the coefficients of neither homeland approach is affected by this procedure.
} 
Table A 3: Fixed effects estimates of eq. (25) using Ethnic homeland and Thiessen homeland MineralGINIs

\begin{tabular}{|c|c|c|}
\hline IncomeGINI $_{\text {Ethnic }}$ & $(1)$ & (2) \\
\hline MineralGINI $I_{\text {Ethnic }}$ & $\begin{array}{c}0.380^{* * *} \\
(15.26)\end{array}$ & $\begin{array}{c}0.391^{* * *} \\
(15.35)\end{array}$ \\
\hline MineralGINI $I_{\text {Thiessen }}$ & $\begin{array}{c}-0.141^{* * *} \\
(-4.69)\end{array}$ & $\begin{array}{c}-0.143^{* * *} \\
(-4.75)\end{array}$ \\
\hline ActiveFacility & & $\begin{array}{l}-0.060^{*} \\
(-1.99)\end{array}$ \\
\hline Constant & $\begin{array}{c}0.193^{* * *} \\
(9.10)\end{array}$ & $\begin{array}{c}0.244^{* * *} \\
(7.38)\end{array}$ \\
\hline$R^{2}$ within & 0.1538 & 0.1556 \\
\hline$R^{2}$ between & 0.2444 & 0.2887 \\
\hline$R^{2}$ overall & 0.2392 & 0.2804 \\
\hline \#Obs. & 1969 & 1969 \\
\hline \# Groups & 152 & 152 \\
\hline
\end{tabular}

Table A 4: Fixed effects estimates of eq. (26) using Thiessen homelands

\begin{tabular}{lcc}
\hline $\ln ($ L $)$ & $(1)$ & $(2)$ \\
\hline $\ln ($ LMine $)$ & $0.155^{* * *}$ & $0.173^{* * *}$ \\
& $(13.39)$ & $(14.06)$ \\
$\ln ($ Pop $)$ & $1.060^{* * *}$ & $1.049^{* * *}$ \\
& $(21.16)$ & $(21.01)$ \\
& & \\
MineralGINI Thiessen $^{* * *}$ & $-1.743^{* * *}$ & $-1.925^{* * *}$ \\
& $(-9.11)$ & $(-9.85)$ \\
Active & & \\
Facility & & $-1.205^{* * *}$ \\
& & $(-4.16)$ \\
Constant & $-5.402^{* * *}$ & $-4.173^{* * *}$ \\
& $(-7.20)$ & $(-12.11)$ \\
$R^{2}$ within & & \\
$R^{2}$ between & 0.2955 & 0.3021 \\
$R^{2}$ overall & 0.6289 & 0.6373 \\
& 0.6220 & 0.6314 \\
\# Obs. & & \\
\# Groups & 2008 & 2008 \\
\hline
\end{tabular}

$t$ statistics in parentheses

${ }^{*} p<0.05,{ }^{* *} p<0.01,{ }^{* * *} p<0.001$ 
Table A 5: Fixed effects estimates of eq. (26) using Ethnic homeland and Thiessen homeland MineralGINIs

\begin{tabular}{|c|c|c|}
\hline $\ln (L)$ & (1) & $(2)$ \\
\hline $\ln ($ LMine $)$ & $\begin{array}{l}0.459^{* * *} \\
(26.96)\end{array}$ & $\begin{array}{l}0.566^{* * *} \\
(32.05)\end{array}$ \\
\hline $\ln (P o p)$ & $\begin{array}{l}1.739^{* * *} \\
(22.14)\end{array}$ & $\begin{array}{l}1.572^{* * *} \\
(20.98)\end{array}$ \\
\hline MineralGINI $_{\text {Ethnic }}$ & $\begin{array}{c}-0.288^{* *} \\
(-2.92)\end{array}$ & $\begin{array}{l}-0.098 \\
(-1.05)\end{array}$ \\
\hline MineralGINI ${ }_{\text {Thiessen }}$ & $\begin{array}{c}0.653^{* * *} \\
(5.61)\end{array}$ & $\begin{array}{c}0.601^{* * *} \\
(5.46)\end{array}$ \\
\hline $\begin{array}{l}\text { Active } \\
\text { Facility }\end{array}$ & & $\begin{array}{c}-1.753^{* * *} \\
(-14.59)\end{array}$ \\
\hline Constant & $\begin{array}{c}-20.621^{* * *} \\
(-16.99)\end{array}$ & $\begin{array}{c}-17.418^{* * *} \\
(-14.94)\end{array}$ \\
\hline$R^{2}$ within & 0.5465 & 0.5965 \\
\hline$R^{2}$ between & 0.5780 & 0.6078 \\
\hline$R^{2}$ overall & 0.5748 & 0.6051 \\
\hline$\# O b s$ & 1865 & 1865 \\
\hline \# Groups & 145 & 145 \\
\hline
\end{tabular}

Table A 6: Estimates of eq. (27) using Thiessen homelands

\begin{tabular}{lcc|c|c} 
Conflict & $(1)$ & $(2)$ & $\begin{array}{c}\text { Logit } \\
(3)\end{array}$ & $\begin{array}{c}\text { Probit }^{20} \\
(4)\end{array}$ \\
\hline Mineral & $0.077^{* * *}$ & $0.077^{* * *}$ & $0.107^{* * *}$ & $0.099^{* * *}$ \\
GINI $_{\text {Thiessen }}$ & $(5.63)$ & $(5.40)$ & $(4.35)$ & $(4.57)$ \\
Active & & -0.005 & & \\
Facility & & $(-0.77)$ & & \\
Constant & 0.007 & 0.011 & $0.037^{* * *}$ & $0.037^{* * *}$ \\
& $(0.37)$ & $(0.65)$ & $(8.68)$ & $(8.66)$ \\
(Pseudo) $R^{2}$ & 0.0168 & 0.0168 & 0.0641 & 0.0629 \\
\# Obs. & 1915 & 1915 & 1915 & 1915 \\
\hline
\end{tabular}

$t$ statistics in parentheses

${ }^{*} p<0.05,{ }^{* *} p<0.01,{ }^{* * *} p<0.001$

\footnotetext{
${ }^{20}$ In the case of logit and probit models, we refrain from including ActiveFacility, because ActiveFacility = 0 perfectly predicts Conflict $=0$ and thus has to be omitted.
} 
B Granger Causality

Table B 1: Harris-Tzavalis unit root test H1

\begin{tabular}{lccc}
\hline & Statistic & $\mathrm{z}$ & $\mathrm{p}$-Value \\
\hline Lhome & 0.6055 & -34.0540 & 0.0000 \\
Lmine & 0.6144 & -32.3751 & 0.0000 \\
\hline
\end{tabular}

Table B 2: Granger causality H1

\begin{tabular}{|c|c|c|c|c|c|c|}
\hline Lhome $_{i, t}$ & (1) & (2) & (3) & (4) & (5) & (6) \\
\hline Lmine $_{i, t}$ & $\begin{array}{c}11.36^{* * *} \\
(6.67)\end{array}$ & $\begin{array}{c}10.83^{* * *} \\
(6.91)\end{array}$ & $\begin{array}{c}12.52^{* * *} \\
(5.42)\end{array}$ & $\begin{array}{c}12.18^{* * *} \\
(5.32)\end{array}$ & $\begin{array}{c}10.69^{* * *} \\
(6.01)\end{array}$ & $\begin{array}{c}10.47^{* * *} \\
(5.41)\end{array}$ \\
\hline Lmine $_{i, t-1}$ & $\begin{array}{l}2.176^{* *} \\
(2.89)\end{array}$ & $\begin{array}{l}1.643^{*} \\
(2.50)\end{array}$ & & & $\begin{array}{l}0.348 \\
(0.55)\end{array}$ & $\begin{array}{l}2.081 \\
(0.68)\end{array}$ \\
\hline Lmine $_{i, t-2}$ & & $\begin{array}{l}1.303^{*} \\
(2.11)\end{array}$ & & & $\begin{array}{l}6.036^{* *} \\
(3.03)\end{array}$ & $\begin{array}{l}4.648 \\
(1.94)\end{array}$ \\
\hline Lmine $_{i, t+1}$ & & & $\begin{array}{l}0.119 \\
(0.28)\end{array}$ & $\begin{array}{l}0.119 \\
(0.38)\end{array}$ & $\begin{array}{l}-0.241 \\
(-0.40)\end{array}$ & $\begin{array}{l}-0.325 \\
(-0.57)\end{array}$ \\
\hline Lmine $_{i, t+1}$ & & & & $\begin{array}{l}-0.234 \\
(-0.77)\end{array}$ & & $\begin{array}{l}-0.172 \\
(-0.27)\end{array}$ \\
\hline Pop & $\begin{array}{c}0.0724^{*} \\
(2.00)\end{array}$ & $\begin{array}{c}0.0888 \\
(1.92)\end{array}$ & $\begin{array}{c}0.0535^{*} \\
(2.29)\end{array}$ & $\begin{array}{c}0.0473 * \\
(2.34)\end{array}$ & $\begin{array}{c}0.0876 \\
(1.77)\end{array}$ & $\begin{array}{c}0.0850 \\
(1.69)\end{array}$ \\
\hline Constant & $\begin{array}{c}-329073.4^{*} \\
(-2.41)\end{array}$ & $\begin{array}{c}-400957.4^{*} \\
(-2.32)\end{array}$ & $\begin{array}{c}-230129.6^{*} \\
(-2.46)\end{array}$ & $\begin{array}{c}-196021.6^{*} \\
(-2.31)\end{array}$ & $\begin{array}{c}-451692.3^{* *} \\
(-2.73)\end{array}$ & $\begin{array}{c}-439330.3^{* *} \\
(-2.78)\end{array}$ \\
\hline$R^{2}$ within & 0.4793 & 0.4767 & 0.4221 & 0.3808 & 0.4534 & 0.4167 \\
\hline$R^{2}$ between & 0.3243 & 0.3290 & 0.3072 & 0.2988 & 0.3215 & 0.3131 \\
\hline$R^{2}$ overall & 0.3226 & 0.3264 & 0.3062 & 0.2977 & 0.3185 & 0.3099 \\
\hline $\begin{array}{l}\text { \# Obs. } \\
\text { \# Groups }\end{array}$ & $\begin{array}{c}15660 \\
1357\end{array}$ & $\begin{array}{c}14348 \\
1344\end{array}$ & $\begin{array}{c}15676 \\
1367\end{array}$ & $\begin{array}{c}14370 \\
1365\end{array}$ & $\begin{array}{c}13041 \\
1338\end{array}$ & $\begin{array}{c}11735 \\
1333\end{array}$ \\
\hline
\end{tabular}

$t$ statistics in parentheses

${ }^{*} p<0.05,{ }^{* *} p<0.01,{ }^{* * *} p<0.001$ 


\section{Additional Tables}

Table C 1: First differences estimates of eq. (24)

\begin{tabular}{|c|c|c|c|}
\hline$\Delta$ Lhome $_{i}$ & (1) & (2) & (3) \\
\hline$\Delta$ Lmine $_{i}$ & $\begin{array}{c}10.96^{* * *} \\
(5.36)\end{array}$ & $\begin{array}{c}10.96^{* * *} \\
(5.36)\end{array}$ & \\
\hline$\Delta$ Lmine $_{-i}$ & $\begin{array}{c}-0.0273 \\
(-0.38)\end{array}$ & & $\begin{array}{c}-0.0228 \\
(-0.29)\end{array}$ \\
\hline$\triangle P o p$ & $\begin{array}{c}-0.0101 \\
(-0.64)\end{array}$ & $\begin{array}{r}-0.0101 \\
(-0.64)\end{array}$ & $\begin{array}{c}-0.00374 \\
(-0.25)\end{array}$ \\
\hline$R^{2}$ & 0.2886 & 0.2885 & 0.0154 \\
\hline \#Obs. & 15576 & 15576 & 15576 \\
\hline
\end{tabular}

Table C 2: OLS estimates of eq. (26)

\begin{tabular}{|c|c|c|c|}
\hline $\ln (L)$ & (1) & (2) & (3) \\
\hline $\ln$ (LMine) & $\begin{array}{l}0.386^{* * *} \\
(39.15)\end{array}$ & $\begin{array}{l}0.548^{* * *} \\
(38.91)\end{array}$ & $\begin{array}{l}0.242^{* * *} \\
(19.64)\end{array}$ \\
\hline $\ln (P o p)$ & $\begin{array}{l}0.714^{* * *} \\
(33.50)\end{array}$ & $\begin{array}{l}0.589^{* * *} \\
(27.11)\end{array}$ & $\begin{array}{l}0.799^{* * *} \\
(48.46)\end{array}$ \\
\hline MineralGINI & $\begin{array}{l}-2.090^{* * *} \\
(-21.78)\end{array}$ & $\begin{array}{l}-1.496^{* * *} \\
(-15.15)\end{array}$ & $\begin{array}{l}-0.192^{*} \\
(-2.46)\end{array}$ \\
\hline AcitveFacility & & $\begin{array}{l}-2.562^{* * *} \\
(-15.37)\end{array}$ & $\begin{array}{l}-1.287^{* * *} \\
(-10.38)\end{array}$ \\
\hline $\begin{array}{l}\text { High income: } \\
\text { non } O E C D\end{array}$ & & & $\begin{array}{l}-0.205^{*} \\
(-2.11)\end{array}$ \\
\hline $\begin{array}{l}\text { Upper middle } \\
\text { income }\end{array}$ & & & $\begin{array}{c}-0.556^{* * *} \\
(-7.92)\end{array}$ \\
\hline $\begin{array}{l}\text { Lower middle } \\
\text { income }\end{array}$ & & & $\begin{array}{l}-1.264^{* * *} \\
(-19.71)\end{array}$ \\
\hline Low income & & & $\begin{array}{l}-2.914^{* * *} \\
(-38.90)\end{array}$ \\
\hline Constant & $\begin{array}{c}-1.955^{* * *} \\
(-6.30)\end{array}$ & $\begin{array}{l}0.497 \\
(1.49)\end{array}$ & $\begin{array}{l}-0.314 \\
(-1.25)\end{array}$ \\
\hline $\begin{array}{l}R^{2} \\
\# \text { Obs. }\end{array}$ & $\begin{array}{c}0.7016 \\
2046\end{array}$ & $\begin{array}{c}0.7327 \\
2046\end{array}$ & $\begin{array}{c}0.8634 \\
2046\end{array}$ \\
\hline
\end{tabular}

$t$ statistics in parentheses

${ }^{*} p<0.05,{ }^{* *} p<0.01,{ }^{* * *} p<0.001$ 
Table C 3: Estimates of eq. (27) - split sample (oil)

\begin{tabular}{lcc|cc|cc}
\hline & \multicolumn{2}{c}{ LPM } & \multicolumn{2}{c}{ Logit } & \multicolumn{2}{c}{ Probit } \\
Conflict & (oil poor) & (oil rich) & (oil poor) & (oil rich) & (oil poor) & (oil rich) \\
\hline Mineral & $0.048^{* * *}$ & $0.054^{*}$ & $0.072^{* *}$ & 0.069 & $0.068^{* *}$ & 0.059 \\
GINI & $(3.53)$ & $(1.99)$ & $(2.99)$ & $(1.77)$ & $(3.17)$ & $(1.76)$ \\
& & & & & & \\
Active & -0.020 & $0.103^{*}$ & -0.041 & omitted & -0.038 & omitted \\
Facility & $(-1.38)$ & $(2.17)$ & $(-1.66)$ & & $(-1.72)$ & \\
Rough & -0.00003 & $0.0002^{*}$ & -0.00002 & $0.0001^{* *}$ & -0.00002 & $0.0001^{*}$ \\
Mean & $(-1.87)$ & $(2.23)$ & $(-1.66)$ & $(2.61)$ & $(-1.56)$ & $(2.58)$ \\
& & & & & & \\
Rough & $0.00006^{*}$ & -0.0001 & $0.00004^{*}$ & -0.0001 & $0.00004^{*}$ & -0.0001 \\
Std & $(2.03)$ & $(-1.92)$ & $(2.31)$ & $(-1.67)$ & $(2.23)$ & $(-1.70)$ \\
& & & & & & \\
Constant & 0.045 & -0.088 & $0.031^{* * *}$ & $0.044^{* * *}$ & $0.031^{* * *}$ & $0.044^{* * *}$ \\
(Pseudo)R $R^{2}$ & $(1.68)$ & $(-1.62)$ & $(7.15)$ & $(5.05)$ & $(7.14)$ & $(5.02)$ \\
\# Obs. & 0.0241 & 0.0659 & 0.0892 & 0.1096 & 0.0888 & 0.1066 \\
\hline Sticsin & 1539 & 524 & 1539 & 523 & 1539 & 523 \\
\hline
\end{tabular}

$t$ statistics in parentheses

${ }^{*} p<0.05,{ }^{* *} p<0.01,{ }^{* * *} p<0.001$

Table C 4: Estimates of eq. (27) - fractionalisation

\begin{tabular}{|c|c|c|c|c|c|c|}
\hline \multirow[b]{2}{*}{ Conflict } & \multicolumn{2}{|c|}{ LPM } & \multicolumn{2}{|c|}{ Logit } & \multicolumn{2}{|c|}{ Probit } \\
\hline & $(1)$ & (2) & (3) & (4) & (5) & (6) \\
\hline MineralGINI & $\begin{array}{l}0.025 \\
(1.87)\end{array}$ & $\begin{array}{l}-0.009 \\
(-0.49)\end{array}$ & $\begin{array}{l}0.040^{*} \\
(2.03)\end{array}$ & $\begin{array}{l}0.040^{*} \\
(2.01)\end{array}$ & $\begin{array}{l}0.037^{*} \\
(2.03)\end{array}$ & $\begin{array}{l}0.037^{*} \\
(2.05)\end{array}$ \\
\hline Ethnic & $\begin{array}{l}0.051^{* *} \\
(3.01)\end{array}$ & $\begin{array}{l}0.012 \\
(0.48)\end{array}$ & $\begin{array}{l}0.055^{* *} \\
(2.72)\end{array}$ & $\begin{array}{l}0.055^{* *} \\
(2.69)\end{array}$ & $\begin{array}{l}0.054^{* *} \\
(2.82)\end{array}$ & $\begin{array}{l}0.057^{* *} \\
(2.89)\end{array}$ \\
\hline $\begin{array}{l}\text { MineralGINI } \\
\cdot \text { Ethnic }\end{array}$ & & $\begin{array}{l}0.076 \\
(1.69))\end{array}$ & & $\begin{array}{l}0.083 \\
\text { (see Figure } \\
\text { A 3) }\end{array}$ & & $\begin{array}{l}0.083 \\
\text { (see Figure } \\
\text { A 4) }\end{array}$ \\
\hline $\begin{array}{l}\text { Active } \\
\text { Facility }\end{array}$ & $\begin{array}{l}-0.008 \\
(-0.41)\end{array}$ & $\begin{array}{l}-0.014 \\
(-0.70)\end{array}$ & $\begin{array}{l}-0.020 \\
(-0.85)\end{array}$ & $\begin{array}{l}-0.021 \\
(-0.86)\end{array}$ & $\begin{array}{l}-0.019 \\
(-0.89)\end{array}$ & $\begin{array}{l}-0.020 \\
(-0.89)\end{array}$ \\
\hline $\begin{array}{l}\text { Rough } \\
\text { Mean }\end{array}$ & $\begin{array}{l}-0.00002 \\
(-1.23)\end{array}$ & $\begin{array}{l}-0.00002 \\
(-1.42)\end{array}$ & $\begin{array}{l}-0.00002 \\
(-1.31)\end{array}$ & $\begin{array}{l}-0.00002 \\
(-1.36)\end{array}$ & $\begin{array}{l}-0.00001 \\
(-1.21)\end{array}$ & $\begin{array}{l}-0.00002 \\
(-1.41)\end{array}$ \\
\hline $\begin{array}{l}\text { Rough } \\
\text { Std }\end{array}$ & $\begin{array}{l}0.00005 \\
(1.85)\end{array}$ & $\begin{array}{l}0.00005^{*} \\
(2.05)\end{array}$ & $\begin{array}{l}0.00004^{*} \\
(2.25)\end{array}$ & $\begin{array}{l}0.00004^{*} \\
(2.31)\end{array}$ & $\begin{array}{l}0.00004^{*} \\
(2.24)\end{array}$ & $\begin{array}{l}0.00004^{*} \\
(2.43)\end{array}$ \\
\hline $\begin{array}{l}\text { Constant } \\
\left(\text { Pseudo) } R^{2}\right. \\
\text { \# Obs. }\end{array}$ & $\begin{array}{l}0.018 \\
(0.64) \\
0.0217 \\
1820\end{array}$ & $\begin{array}{l}0.039 \\
(1.27) \\
0.0231 \\
1820\end{array}$ & $\begin{array}{l}0.032^{* * *} \\
(7.92) \\
0.0789 \\
1820\end{array}$ & $\begin{array}{l}0.032^{* * *} \\
(7.88) \\
0.0550 \\
1820\end{array}$ & $\begin{array}{l}0.032^{* * *} \\
(7.91) \\
0.0790 \\
1820\end{array}$ & $\begin{array}{l}0.032^{* * *} \\
(7.89) \\
0.0566 \\
1820\end{array}$ \\
\hline
\end{tabular}

$t$ statistics in parentheses

${ }^{*} p<0.05,{ }^{* *} p<0.01,{ }^{* * *} p<0.001$ 
Table C 5: Estimates of eq. (27) - split sample at fractionalisation median

\begin{tabular}{lll|ll|rr}
\hline \multicolumn{2}{r}{ Conflict } & \multicolumn{2}{c}{ LPM } & \multicolumn{2}{c}{ Logit } & \multicolumn{2}{c}{ Probit } \\
MineralGINI & $0.041^{* *}$ & $0.054^{*}$ & $0.064^{*}$ & $0.069^{*}$ & $0.062^{*}$ & $0.064^{*}$ \\
& $(2.62)$ & $(2.48)$ & $(2.23)$ & $(1.98)$ & $(2.35)$ & $(2.04)$ \\
& & & & & & \\
Active & -0.032 & -0.021 & -0.051 & -0.032 & -0.048 & -0.030 \\
Facility & $(-0.90)$ & $(-0.93)$ & $(-1.41)$ & $(-0.82)$ & $(-1.34)$ & $(-0.86)$ \\
& & & & & & \\
Constant & 0.045 & 0.065 & $0.030^{* * *}$ & $0.041^{* * *}$ & $0.030^{* * *}$ & $0.041^{* * *}$ \\
& $(1.11)$ & $(1.68)$ & $(4.71)$ & $(6.38)$ & $(4.71)$ & $(6.37)$ \\
(Pseudo) $R^{2}$ & 0.0243 & 0.0215 & 0.0755 & 0.0685 & 0.0767 & 0.0675 \\
\# Obs. & 897 & 923 & 690 & 923 & 690 & 923 \\
\hline
\end{tabular}

$t$ statistics in parentheses

${ }^{*} p<0.05,{ }^{* *} p<0.01,{ }^{* * *} p<0.001$

\section{Figures}

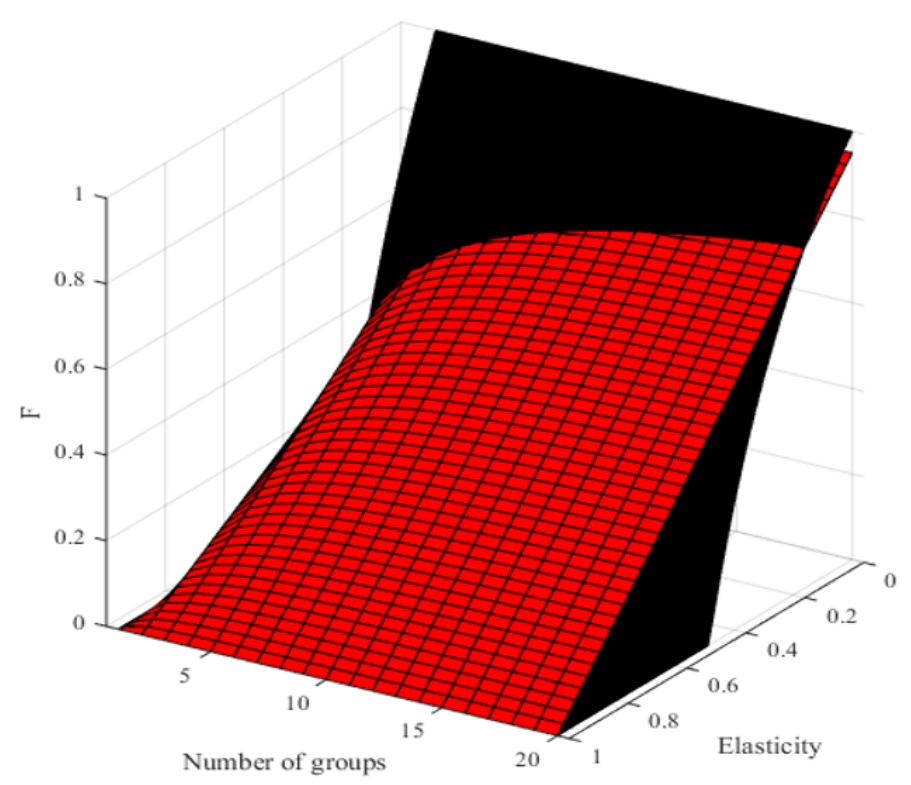

Figure D 1: Total rent-seeking effort 


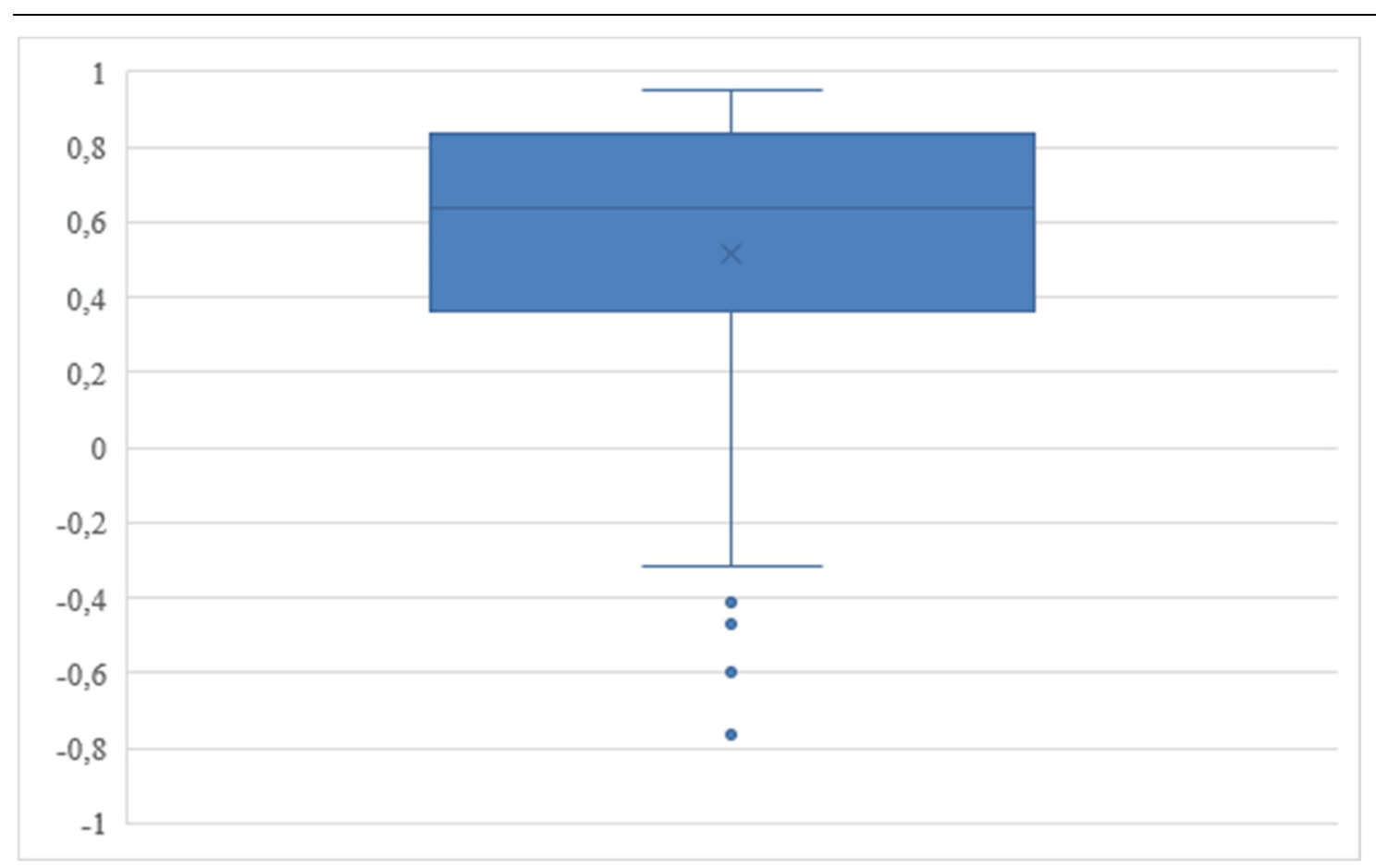

Figure D 2: Boxplot of correlation coefficients between light near mines and resource rents

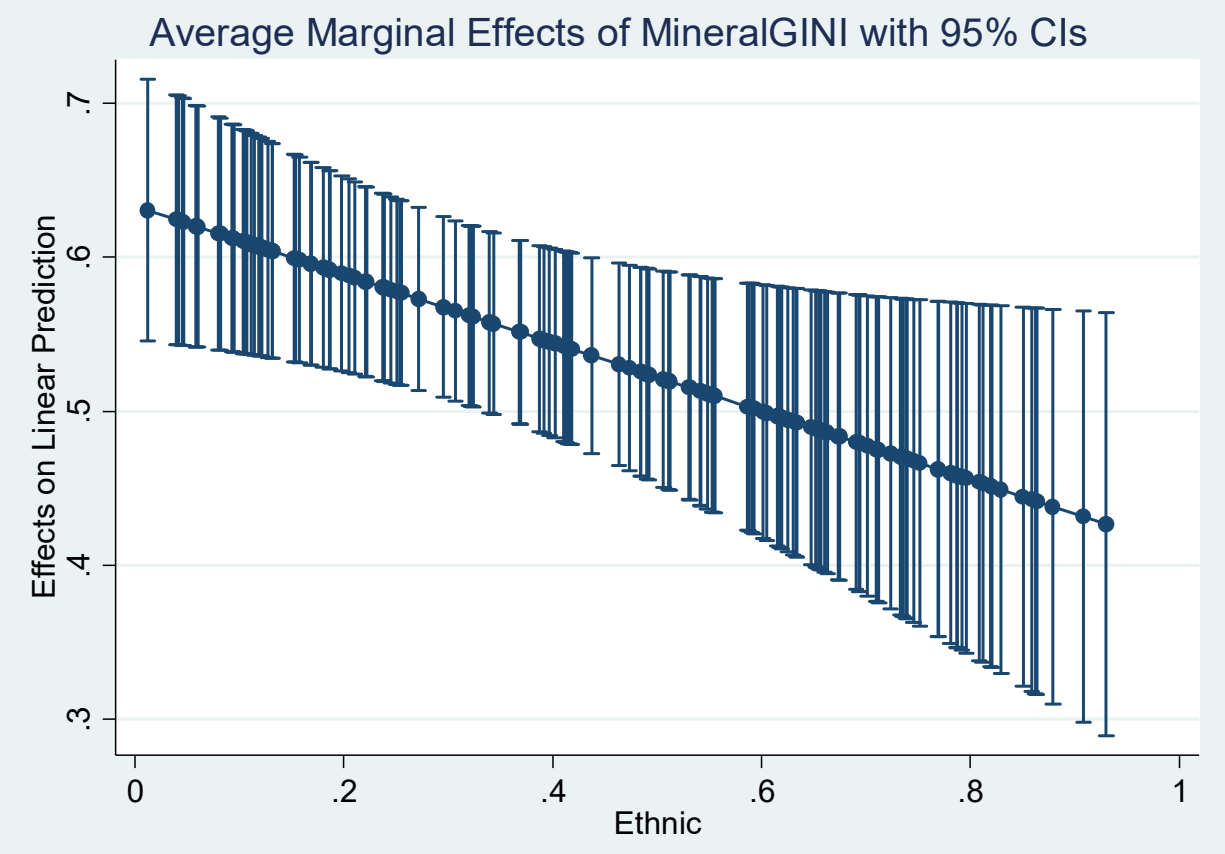

Figure D 3: Marginal effect of MineralGINI on IncomeGINI at different levels of ethnic fractionalization. 


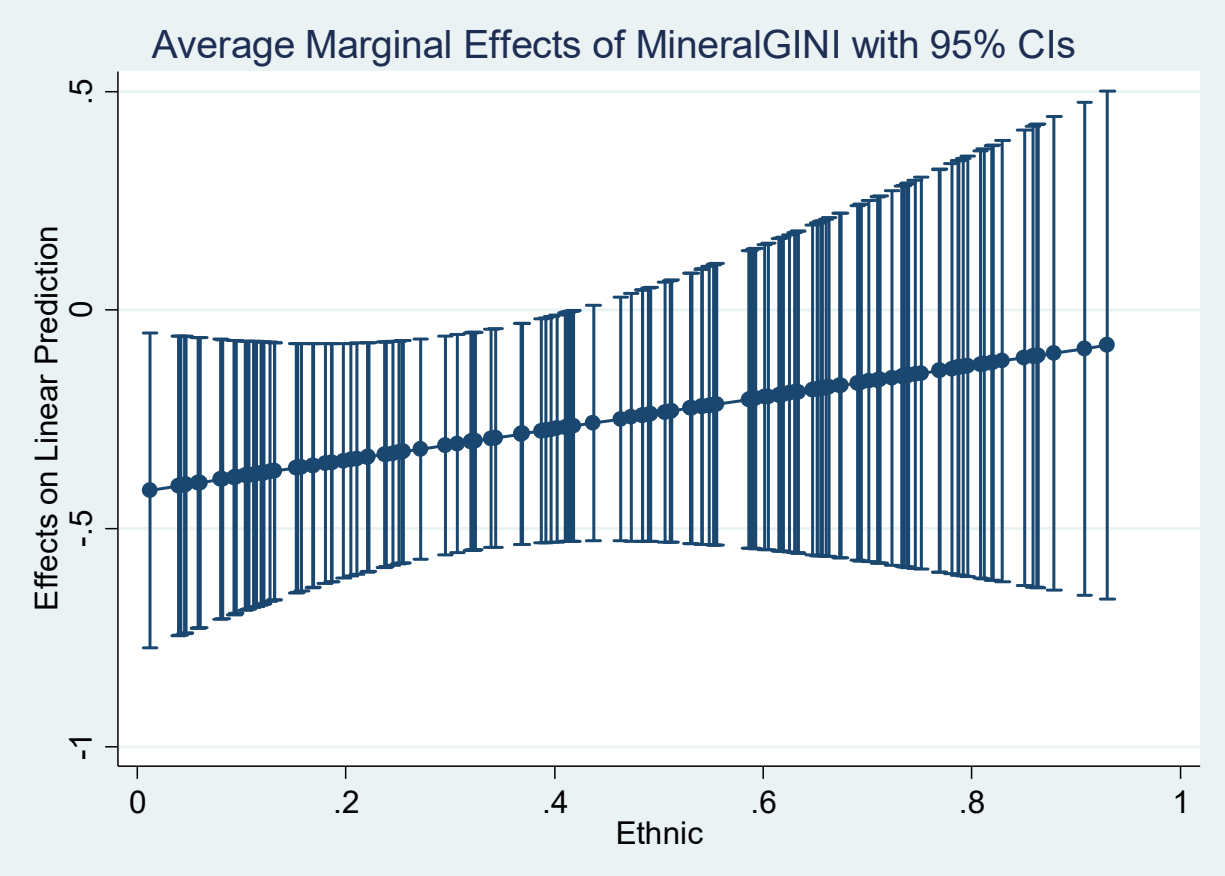

Figure D 4: Marginal effect of MineralGINI on Income at different levels of ethnic fractionalization.

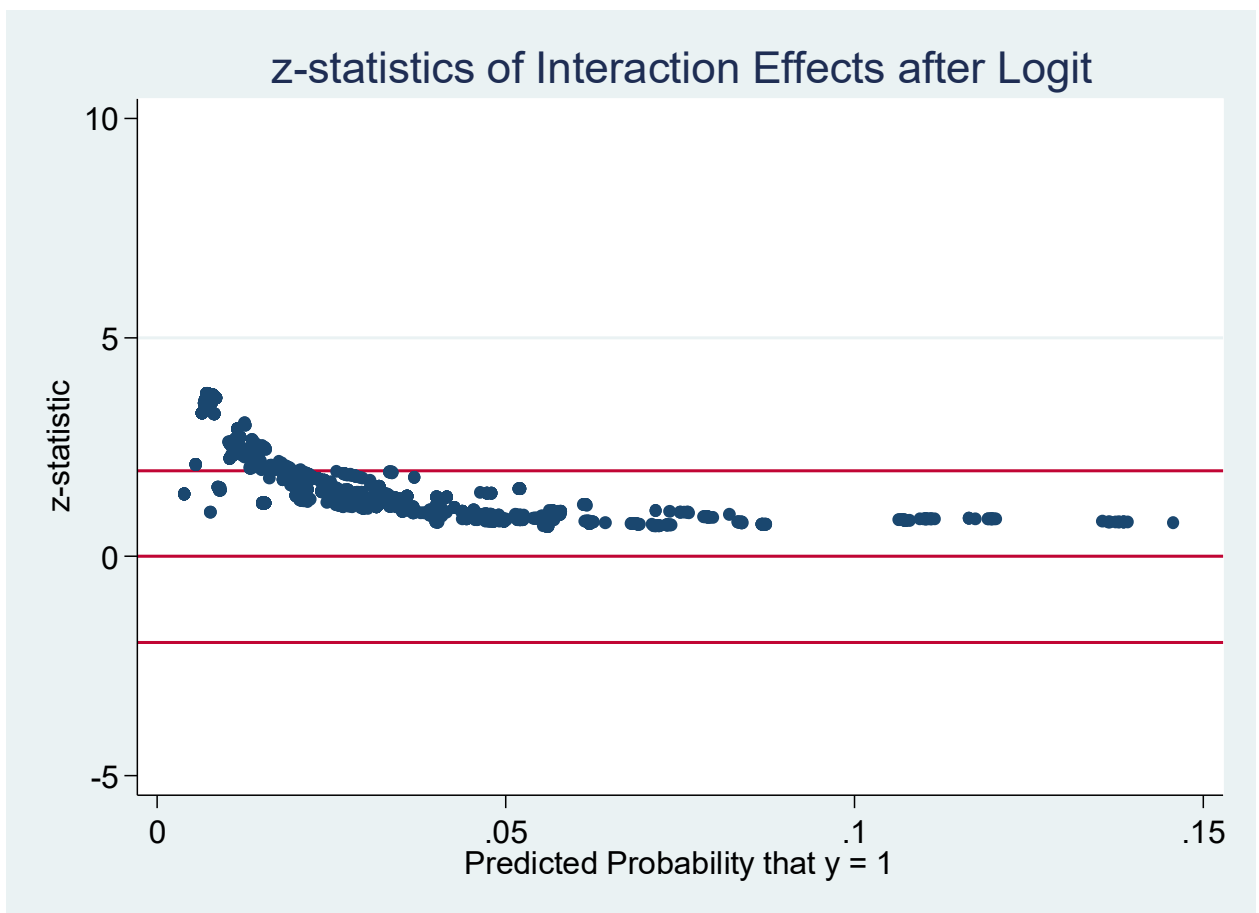

Figure D 5: Significance of MineralGINI Ethnic Interaction term - Table A 11, column (4) 


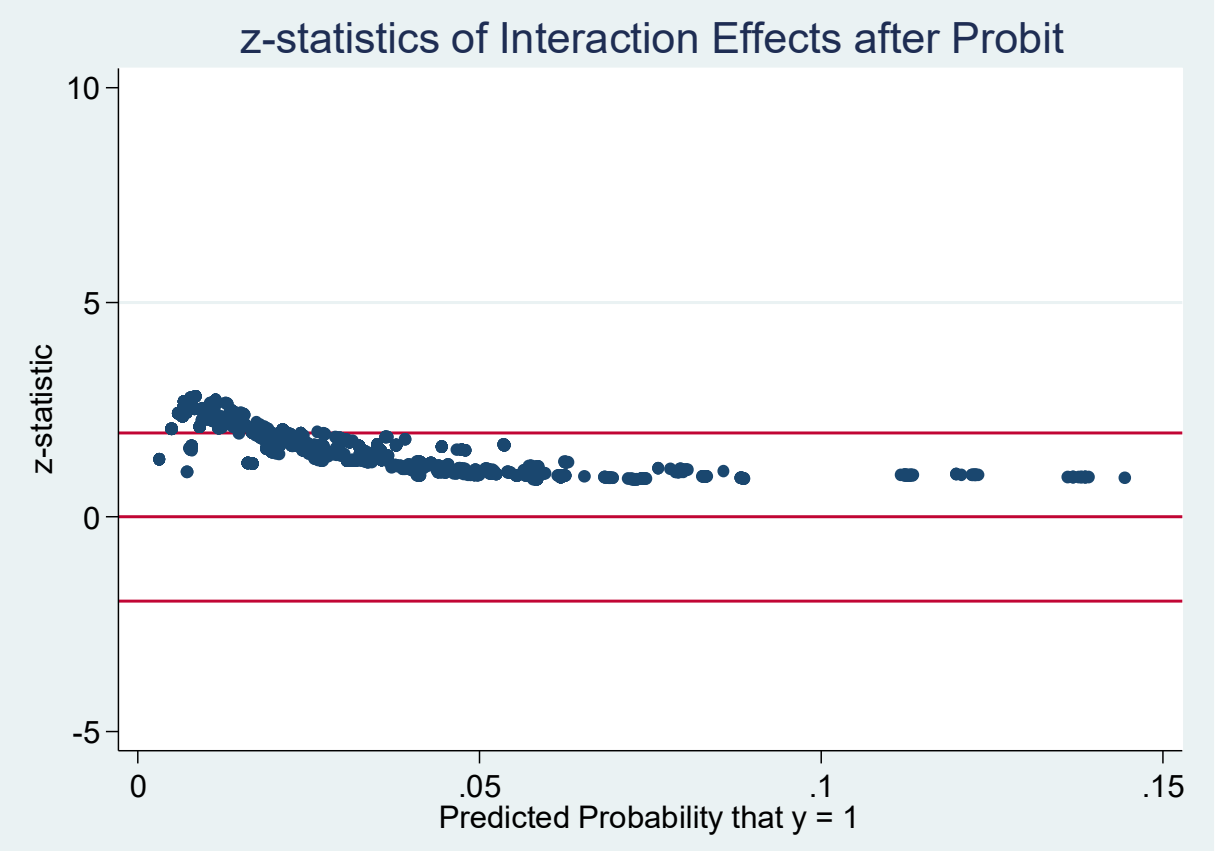

Figure D 6: Significance of MineralGINI Ethnic Interaction term - Table A 11, column (6) 


\section{E Detailed insights}

\section{Detailed insights in $\mathrm{H3}$}

Our theoretical model predicts that the rent-seeking effect of an unequal resource distribution on the economic performance depends on the income elasticity of labour. This prediction is intuitive because the opportunity cost of rent seeking is high if the elasticity is also. Therefore, the resource inequality-induced rent-seeking effort increases, as does the elasticity. On the contrary, if opportunity costs are low, rent seeking seems profitable no matter how resources are distributed.

We analyse the elasticity and GINI effect in two steps. First, we estimate region- and incomespecific (according to the World Bank definition) income elasticities of labour using our CobbDouglas production function, as well as the estimation strategy recommended by Mankiw et al. 1992. From equation (4) it follows that:

$$
\begin{aligned}
& \ln (y)=A+\alpha \cdot \ln (l)+(1-\alpha) \cdot \ln (r) \\
& \ln (y)-\ln (r)=A+\alpha \cdot(\ln (l)-\ln (r)) \\
& \ln (y)-\ln (r)=Y \wedge \ln (l)-\ln (r)=X
\end{aligned}
$$

We approximate the income variable $y$ and the resource variable $r$ using night-time light emissions in the country and nearby mines and employment data $l$ from the World Bank database. To capture the unobserved technological progress variable $A$, as well as other heterogeneities, we estimate the following models using a fixed effects estimation strategy:

$$
Y_{j, t}=I+\alpha_{k} \cdot \text { Category } y_{j} \cdot X_{j, t}+\tau_{t}+\theta_{t}+\varepsilon_{j, t}
$$

Here, $I$ is the intercept, $\alpha_{k}$ denotes the income elasticity of region or income category $k=$ $1, \ldots, K$, and Category $_{j}$ is the region or income category country $j=1, \ldots, J$ belongs to. The results are reported in Table E 1. As expected, it becomes obvious that the income elasticity is high in less-developed and developing countries (see column (2)) and in countries that are located in Sub-Saharan Africa (see column (1)). Based on these results, we analyse the interaction effect of resource inequality and the estimated income elasticity on development in a second step. We estimate the following fixed effects model:

$$
\begin{gathered}
L_{j}=I+\beta \cdot \ln \left(\text { Line }_{j, t}\right)+\gamma \cdot \ln \left(\text { Pop }_{j, t}\right)+\delta_{k} \cdot \alpha_{k} \cdot \text { MineralGINI }_{j, t}+ \\
\rho \cdot \text { MineralGIN }_{j, t}+\varepsilon_{j, t}
\end{gathered}
$$

and find evidence of the dependence of the negative resource inequality effect on income elasticity, as predicted by our theoretical model. The results are reported in Table E 2, where column 
(1) is estimated using region-specific elasticities, and column (2) uses income category-specific elasticities. We find income elasticity thresholds of 0.2 (column (1)) and 0.43 (column (2)) that mark the split of the MineralGINI effect. Consequently, low-income countries and/or countries from Sub-Saharan Africa are especially prone to resource inequality-induced rent seeking. Based on our results, a low-income country suffers from a 14 per cent decrease in real GDP if it has a MineralGINI of 0.75 instead of a homogeneous distribution.

Table E 1: Estimates of income elasticity ${ }^{21}$

\begin{tabular}{|c|c|c|c|}
\hline$Y$ & (1) & $Y$ & $(2)$ \\
\hline$E A S \cdot X$ & $\begin{array}{c}0.637^{* * *} \\
(20.24)\end{array}$ & $\begin{array}{l}\text { High income: } \\
O E C D \cdot X\end{array}$ & $\begin{array}{c}0.362^{* * *} \\
(5.15)\end{array}$ \\
\hline$E C S \cdot X$ & $\begin{array}{l}0.325^{* * *} \\
(935)\end{array}$ & Hiah income. & $0272^{* * *}$ \\
\hline$L C N \cdot X$ & $\begin{array}{c}0.652^{* * *} \\
(9.01)\end{array}$ & nonOECD $\cdot X$ & $(3.68)$ \\
\hline$M E A \cdot X$ & $\begin{array}{l}0.166^{*} \\
(2.43)\end{array}$ & $\begin{array}{l}\text { Upper middle } \\
\text { income } \cdot X\end{array}$ & $\begin{array}{c}0.556^{* * *} \\
(17.06)\end{array}$ \\
\hline$N A C \cdot X$ & $\begin{array}{l}0.263 \\
(0.57)\end{array}$ & Lower middle & $0.550^{* * *}$ \\
\hline$S A S \cdot X$ & $\begin{array}{c}0.577^{* * *} \\
(4.73)\end{array}$ & income $\cdot X$ & $(13.61)$ \\
\hline$S S F \cdot X$ & $\begin{array}{c}0.824^{* * *} \\
(49.28)\end{array}$ & Low income $\cdot X$ & $\begin{array}{c}0.789^{* * *} \\
(47.22)\end{array}$ \\
\hline SatelliteFE & YES & SatelliteFE & YES \\
\hline YearFE & YES & YearFE & YES \\
\hline Constant & $\begin{array}{c}-1.048^{* * *} \\
(-8.41)\end{array}$ & Constant & $\begin{array}{c}-1.230^{* * *} \\
(-12.27)\end{array}$ \\
\hline$R^{2}$ within & 0.6353 & $R^{2}$ within & 0.6107 \\
\hline$R^{2}$ between & 0.2660 & $R^{2}$ between & 0.2513 \\
\hline$R^{2}$ overall & 0.2572 & $R^{2}$ overall & 0.2637 \\
\hline \#Obs. & 2020 & \# Obs. & 2020 \\
\hline \# Groups & 157 & \# Groups & 157 \\
\hline
\end{tabular}

$t$ statistics in parentheses

${ }^{*} p<0.05,{ }^{* *} p<0.01,{ }^{* * *} p<0.001$

\footnotetext{
${ }^{21}$ EAS: East Asia \& Pacific, ECS: Europe \& Central Asia, LCN: Latin America \& Caribbean, MEA: Middle
} East \& North Africa, NAC: North America, SAS: South Asia, SSF: Sub-Saharan Africa. 
Table E 2:Interaction effect of elasticity and resource inequality on income

\begin{tabular}{|c|c|c|}
\hline $\ln (L)$ & (1) & (2) \\
\hline $\ln ($ LMine $)$ & $\begin{array}{l}0.502^{* * *} \\
(27.77)\end{array}$ & $\begin{array}{l}0.507^{* * *} \\
(28.52)\end{array}$ \\
\hline $\ln (P o p)$ & $\begin{array}{l}1.341^{* * *} \\
(20.95)\end{array}$ & $\begin{array}{l}1.344^{* * *} \\
(21.07)\end{array}$ \\
\hline$\alpha_{k} \cdot$ MineralGINI & $\begin{array}{l}-0.999^{*} \\
(-2.24)\end{array}$ & $\begin{array}{c}-2.876^{\text {*** }} \\
(-3.98)\end{array}$ \\
\hline MineralGINI & $\begin{array}{l}0.200 \\
(0.83)\end{array}$ & $\begin{array}{c}1.247^{* *} \\
(3.13)\end{array}$ \\
\hline Constant & $\begin{array}{l}-14.00^{* * *} \\
(-14.19)\end{array}$ & $\begin{array}{c}-13.99^{* * *} \\
(-14.22)\end{array}$ \\
\hline $\begin{array}{l}R^{2} \text { within } \\
R^{2} \text { between } \\
R^{2} \text { overall }\end{array}$ & $\begin{array}{l}0.4900 \\
0.6433 \\
0.6469\end{array}$ & $\begin{array}{l}0.4929 \\
0.6707 \\
0.6741\end{array}$ \\
\hline $\begin{array}{l}\text { \# Obs. } \\
\text { \# Groups }\end{array}$ & $\begin{array}{c}2046 \\
159\end{array}$ & $\begin{array}{c}2046 \\
159\end{array}$ \\
\hline
\end{tabular}

\section{Detailed insights in H4}

Similarly to $\mathrm{H} 3$, our theoretical model predicts that the rent-seeking effect of an unequal resource distribution on the probability of the onset of civil conflict depends on the income elasticity of labour. Therefore, we analyse the interaction effect of resource inequality and the estimated income elasticity on the probability of the onset of civil conflicts. We estimate the following model using LPM, logit and probit estimation strategies:

$$
\begin{aligned}
\text { Conflict }_{j, t}= & I+\beta \cdot \alpha_{k} \cdot \text { MineralGINI }_{j, t}+\gamma \cdot \alpha_{k}+\delta \cdot \text { MineralGINI }_{j, t}+\text { Rough }_{j} \\
& +\psi_{j, t}+\tau_{t}+\theta_{\mathrm{t}}+\varepsilon_{j, t}
\end{aligned}
$$

The results are reported in Table E 3, where the first column of each estimation strategy contains region-specific elasticities, and the additional column contains income category-specific income elasticities. In the logit and probit models, we report APEs, which already contain the average interaction effect with respect to the considered variable. For the sake of completeness, we use the inteff command provided by Norton et al. (2004) to additionally evaluate the interaction terms. Our estimates reveal the importance of taking resource distribution as well as 
income elasticities of labour into account because most coefficients are statistically significant and economically relevant even after controlling for the roughness of the terrain. It has to be mentioned that these empirical results are not fully in line with our theoretical model because the coefficients of income elasticity have the wrong signs. However, we are sure that this feature comes from the unobserved effects of political institutions, which are said to have the power to turn a resource curse into a blessing (see, e.g., Mehlum et al. 2006, Robinson et al. 2006, Rohner et al. 2013). Indeed, countries with low income elasticities of labour normally also have good institutions, whereas poorer ones, which have a high elasticity, suffer from cronyism and corruption. 


\begin{tabular}{|c|c|c|c|c|c|c|}
\hline \multirow[b]{2}{*}{ Conflict } & \multicolumn{2}{|c|}{ LPM } & \multicolumn{2}{|c|}{ Logit } & \multicolumn{2}{|c|}{ Probit } \\
\hline & (Region) & (Income) & (Region) & (Income) & (Region) & (Income) \\
\hline MineralGINI & $\begin{array}{l}0.027 \\
(1.04)\end{array}$ & $\begin{array}{c}-0.099^{*} \\
(-2.29)\end{array}$ & $\begin{array}{c}0.065^{* *} \\
(3.05)\end{array}$ & $\begin{array}{l}0.040^{*} \\
(-2.01)\end{array}$ & $\begin{array}{c}0.061^{* *} \\
(3.22)\end{array}$ & $\begin{array}{l}0.039^{*} \\
(2.19)\end{array}$ \\
\hline$\alpha_{k}$ & $\begin{array}{l}0.012 \\
(0.48)\end{array}$ & $\begin{array}{l}0.034 \\
(0.80)\end{array}$ & $\begin{array}{l}0.004 \\
(0.20)\end{array}$ & $\begin{array}{c}0.157^{* * *} \\
(4.18)\end{array}$ & $\begin{array}{l}0.025 \\
(1.20)\end{array}$ & $\begin{array}{c}0.146^{* * *} \\
(4.26)\end{array}$ \\
\hline $\begin{array}{l}\text { MineralGINI } \\
\cdot \alpha_{k}\end{array}$ & $\begin{array}{l}0.032 \\
(0.65)\end{array}$ & $\begin{array}{l}0.204^{* *} \\
(2.69)\end{array}$ & $\begin{array}{c}-0.024 \\
\text { (see Table E } 4 \\
\text { (1)) }\end{array}$ & $\begin{array}{c}0.240 \\
\text { (see Table E } 4 \\
(2))\end{array}$ & $\begin{array}{c}0.022 \\
\text { (see Table E } 4 \\
(3))\end{array}$ & $\begin{array}{c}0.149 \\
\text { (see Table E } 4 \\
(4))\end{array}$ \\
\hline $\begin{array}{l}\text { Active } \\
\text { Facility }\end{array}$ & $\begin{array}{l}-0.015 \\
(-1.00)\end{array}$ & $\begin{array}{l}-0.003 \\
(-0.20)\end{array}$ & $\begin{array}{l}-0.039 \\
(-1.71)\end{array}$ & $\begin{array}{l}-0.008 \\
(-0.32)\end{array}$ & $\begin{array}{l}-0.026 \\
(-1.18)\end{array}$ & $\begin{array}{l}-0.009 \\
(-0.42)\end{array}$ \\
\hline TopoMean & $\begin{array}{c}-0.00001 \\
(-1.13)\end{array}$ & $\begin{array}{c}-0.00003^{*} \\
(-2.16)\end{array}$ & $\begin{array}{c}-0.00001 \\
(-1.19)\end{array}$ & $\begin{array}{c}-0.00003^{*} \\
(-2.24)\end{array}$ & $\begin{array}{c}-0.00001 \\
(-0.96)\end{array}$ & $\begin{array}{c}-0.00002^{*} \\
(-2.03)\end{array}$ \\
\hline TopoStd & $\begin{array}{c}0.00004 \\
(1.70)\end{array}$ & $\begin{array}{c}0.00006^{*} \\
(2.39)\end{array}$ & $\begin{array}{c}0.00002 \\
(1.65)\end{array}$ & $\begin{array}{c}0.00005^{* *} \\
(3.01)\end{array}$ & $\begin{array}{c}0.00003^{*} \\
(1.85)\end{array}$ & $\begin{array}{c}0.00004^{* *} \\
(2.81)\end{array}$ \\
\hline Constant & $\begin{array}{l}0.035 \\
(1.23)\end{array}$ & $\begin{array}{l}0.021 \\
(0.58)\end{array}$ & $\begin{array}{c}0.028^{* * *} \\
(7.77)\end{array}$ & $\begin{array}{c}0.034^{* * *} \\
(8.71)\end{array}$ & $\begin{array}{l}0.034^{* * *} \\
(8.64)\end{array}$ & $\begin{array}{c}0.034^{* * *} \\
(8.69)\end{array}$ \\
\hline $\begin{array}{l}\left(\text { Pseudo)R } R^{2}\right. \\
\# \text { Obs. }\end{array}$ & $\begin{array}{c}0.0209 \\
2063 \\
\end{array}$ & $\begin{array}{c}0.0338 \\
2063 \\
\end{array}$ & $\begin{array}{c}0.0481 \\
2063 \\
\end{array}$ & $\begin{array}{c}0.0860 \\
2063\end{array}$ & $\begin{array}{c}0.0511 \\
2063\end{array}$ & $\begin{array}{c}0.0841 \\
2063\end{array}$ \\
\hline
\end{tabular}

$t$ resp. $z$ statistics in parentheses

${ }^{*} p<0.05,{ }^{* *} p<0.01,{ }^{* * *} p<0.001$ 
Table E 4: Significance of interaction terms

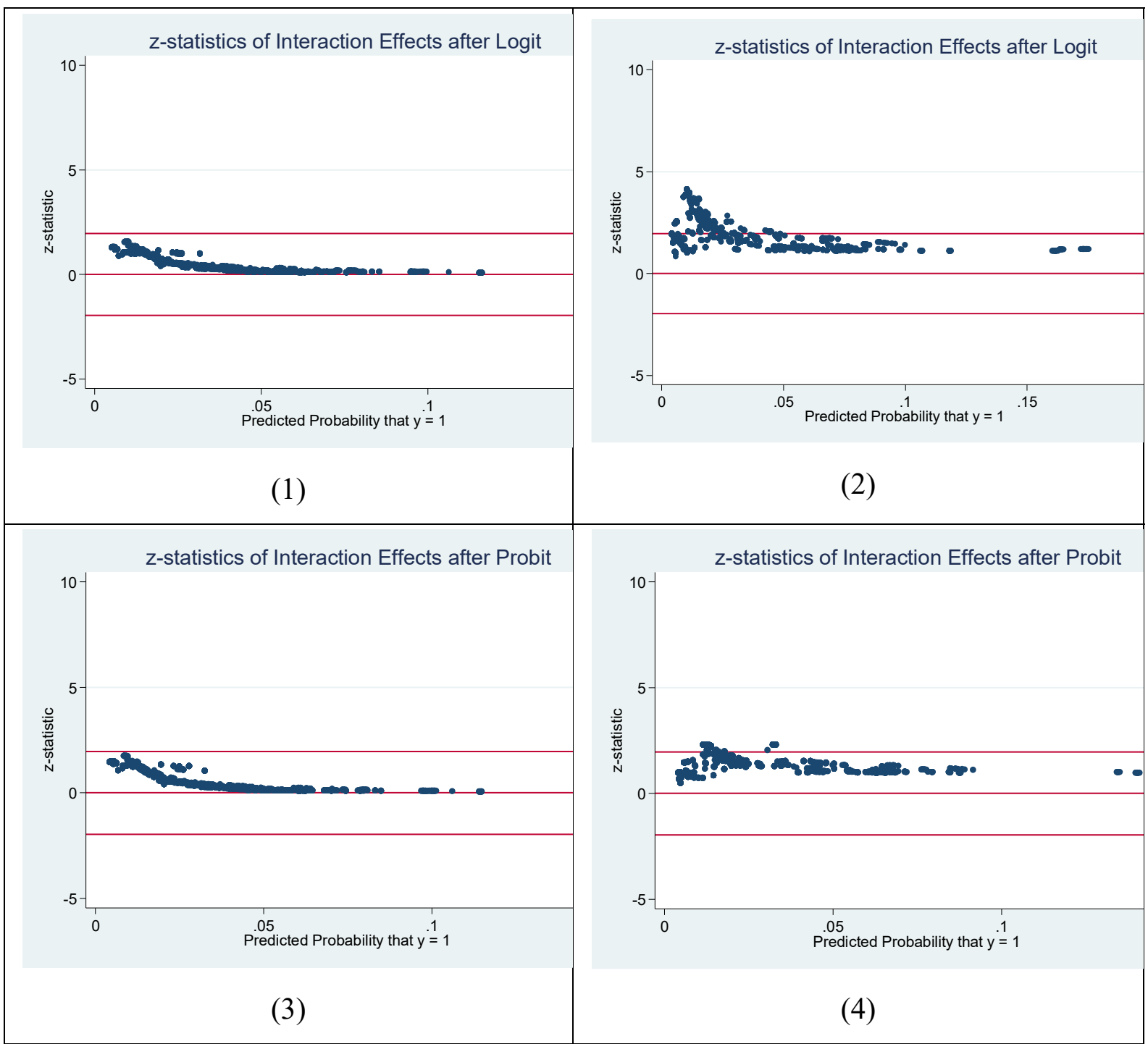

